\title{
CABI UK and Nagoya Protocol triggered benefit sharing
}

\section{Authors}

David Smith

Matthew J. Ryan

Belinda Luke

Djamila Djeddour

Marion K. Seier
Sonal Varia

Kate M. Pollard

Corin F. Pratt

Daisuke Kurose

Richard H. Shaw

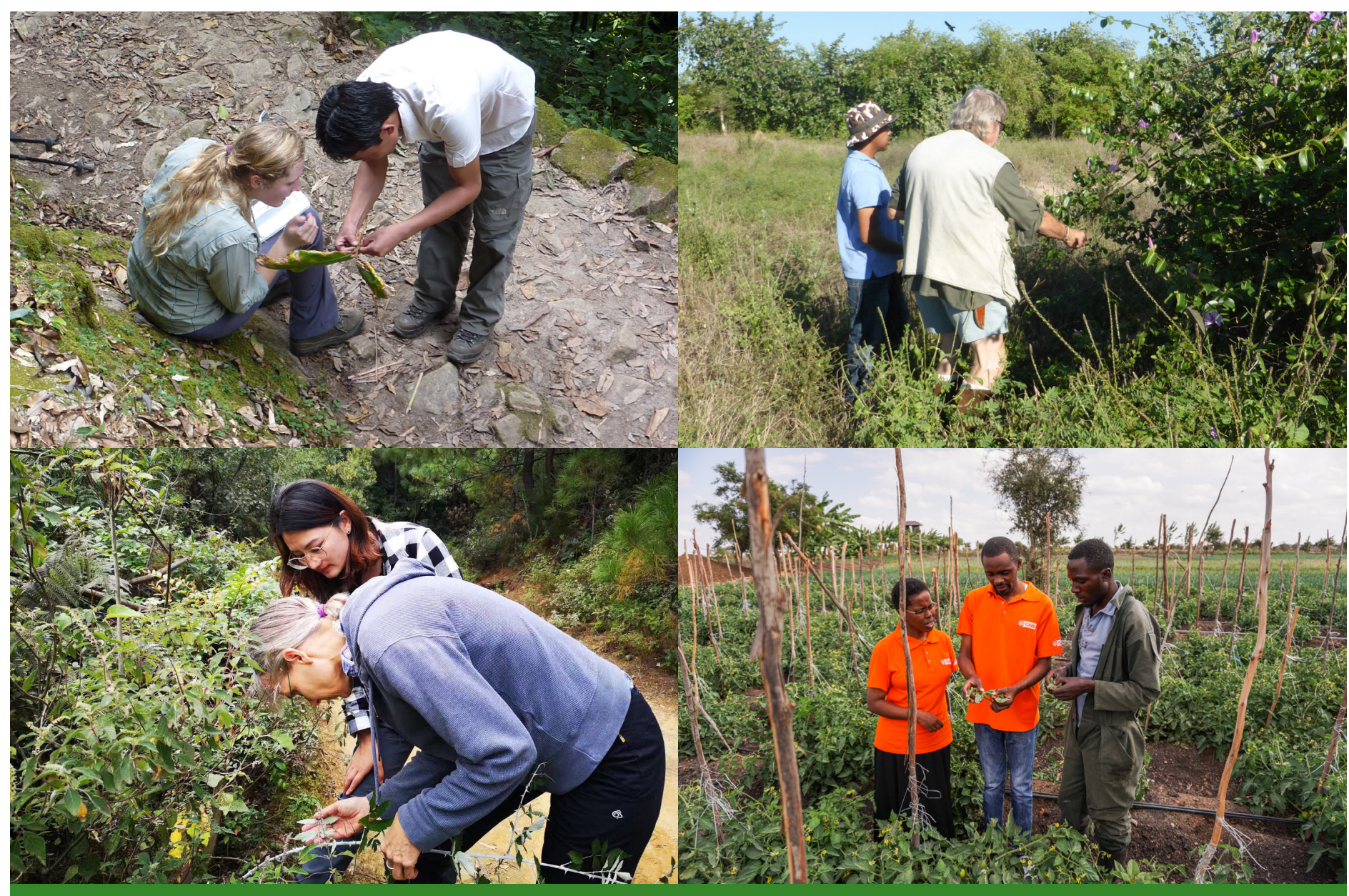




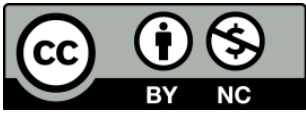

The copyright holder of this work is $\mathrm{CAB}$ International (trading as $\mathrm{CABI}$ ). It is made available under a Creative Commons Attribution-Non-commercial Licence (CC BY-NC). For further details please refer to http://creativecommons.org/license.

This publication has been developed partly with CABI Development Fund support on compliance with the Nagoya Protocol. CABI is an international intergovernmental organization, and we gratefully acknowledge the core financial support from our member countries (and lead agencies) including the United Kingdom (Foreign, Commonwealth and Development Office), China (Chinese Ministry of Agriculture and Rural Affairs), Australia (Australian Centre for International Agricultural Research), Canada (Agriculture and Agri-Food Canada), the Netherlands (Directorate-General for International Cooperation) and Switzerland (Swiss Agency for Development and Cooperation); https://www.cabi.org/what-we-do/how-we-work/cabi-donors-and-partners/.

This CABI Working Paper was internally peer-reviewed. It may be referred to as:

Smith, D., Ryan, M.J., Luke, B., Djeddour, D., Seier, M.K., Varia, S., Pollard, K.M., Pratt, C.F., Kurose, D. and Shaw, R.H. (2021) CABI UK and Nagoya Protocol triggered benefit sharing. CABI Working Paper 25, 33 pp. DOI: https://dx.doi.org/10.1079/CABICOMM-62-8160

All authors are based at CABI, Bakeham Lane, Egham, Surrey TW20 9TY, UK

David Smith: Email: d.smith@cabi.org ORCID: 0000-0003-1821-5141 (corresponding author)

Matthew J. Ryan: Email: m.ryan@cabi.org ORCID: 0000-0002-3689-6609

Belinda Luke: Email: b.luke@cabi.org ORCID: 0000-0003-4055-5185

Djamila Djeddour: Email: d.djeddour@cabi.org ORCID: 0000-0002-1421-4101

Marion K. Seier: Email: m.seier@cabi.org ORCID: 0000-0002-6842-0808

Sonal Varia: Email: s.varia@cabi.org ORCID: 0000-0001-7244-9286

Kate M. Pollard: Email: k.pollard@cabi.org ORCID: 0000-0002-0913-6743

Corin F. Pratt: Email: c.pratt@cabi.org ORCID: 0000-0001-8070-7302

Daisuke Kurose: Email: D.Kurose@cabi.org ORCID: 0000-0002-8356-4930

Richard H. Shaw: Email: r.shaw@cabi.org ORCID: 0000-0003-0805-1841

Cover photo credits: top left, Corin F. Pratt, CABI; top right, Marion K. Seier, CABI; bottom left, Prof Hong Jiang, Yunnan Academy of Forestry and Grassland, Kunming City, China; bottom right, CABI. 


\section{Contents}

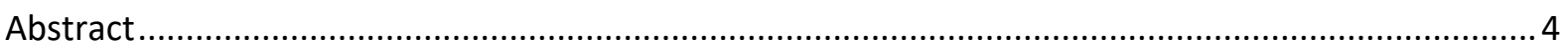

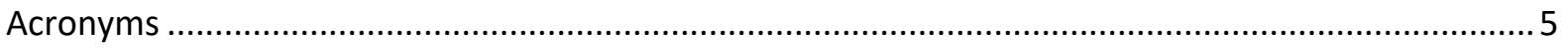

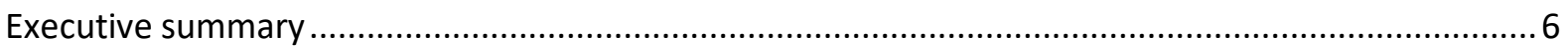

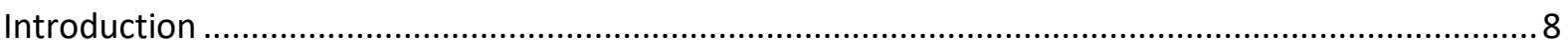

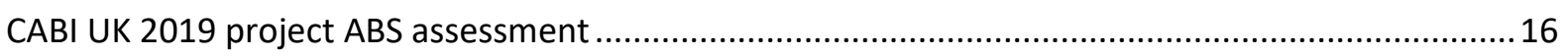

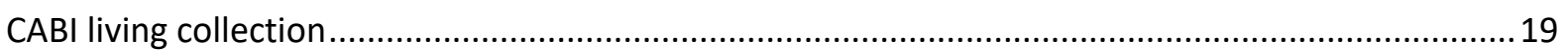

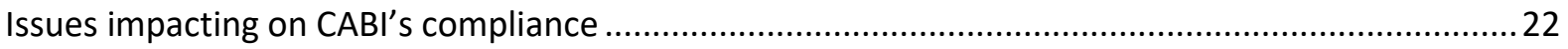

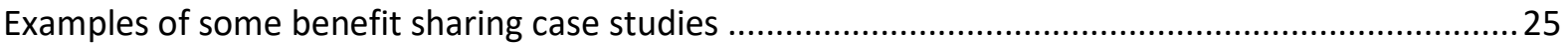

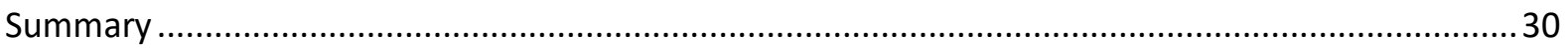

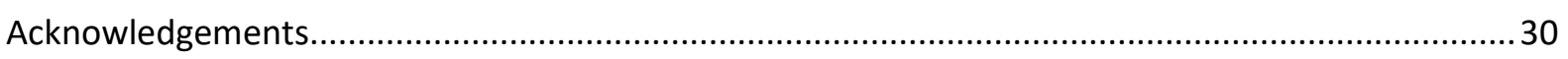

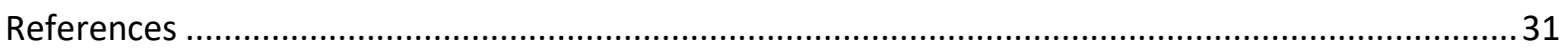




\begin{abstract}
As the tenth anniversary of the adoption of the Nagoya Protocol on Access and Benefit Sharing (ABS) was reached, $C A B I$ reviewed its benefit sharing activities. $C A B I$ published its Nagoya Protocol Access and Benefit Sharing Policy online (CABI 2018a) and took a position to share benefits whether the provider country is party to the Nagoya Protocol or not. CABI is mission driven and dedicated to support its 50 member countries in agriculture and the environment, sharing knowledge and acting to translate science into practical tools for farmers to improve crop production and enhance their livelihoods. $C A B I$ member countries have agreed that $C A B I$ shares the benefits of its work with genetic resources through its mission-based objectives. $C A B I$ has introduced $A B S$ Best Practices in its centres around the world and in most cases, works through in-country partners on funded projects, sharing project outputs. Since enactment of the Nagoya Protocol, CABI UK, Egham has initiated over 200 projects involving genetic resources. In 2019, 116 projects were assessed of which the majority were out of scope of UK regulation. For example nine projects were internally funded, designed to improve services and outputs to users, partners and provider countries. Twenty-four projects were funded by research programmes or organizations; these projects provided services such as identification of organisms, diagnosis of disease and assessment of contamination of seeds. Several of the projects utilized organisms from countries that have no access regulation, for example the UK, where 16 projects utilized UK genetic resources. The majority of the benefits shared were non-monetary and included: sharing of Research and Development (R\&D) results; collaboration in education, training, research, development programmes; joint authorship of publications and joint ownership of intellectual property rights; access to ex situ facilities and databases; transfer of scientific information, knowledge and technology; and institutional capacity-development helping build or maintain local collections. Monetary benefits were limited to sharing project funding for research in both the UK and provider countries. An added benefit is that fungi and bacteria from this work are preserved for future use in the CABI living collection and shared with users and project partners.
\end{abstract}




\section{Acronyms and abbreviations}

ABS

$\mathrm{ABSCH}$

BAFU

CBD

CHAP

CNA

DARE

Defra

DSI

EC

EU

FUEDEI

ICAR

MAT

MoU

MTA

NBA

NHM

NFP

PIC

$R \& D$
Access and Benefit Sharing

Access and Benefit Sharing Clearing House

Bundesamt für Umwelt (Swiss Federal Office for the Environment)

Convention on Biological Diversity

Crop Health and Protection

Competent National Authority

Department of Agricultural Research and Education

Department for Environment, Food and Rural Affairs

Digital Sequence Information

European Commission

European Union

Fundación para el Estudio de Especies Invasivas

Indian Council of Agricultural Research

Mutually Agreed Terms

Memorandum of Understanding

Material Transfer Agreement

National Biodiversity Authority

The Natural History Museum, London

National Focal Point

Prior Informed Consent

Research and Development 


\section{Executive summary}

The Nagoya Protocol provisions govern the transfer of genetic resources and impose national requirements on access, use and benefit sharing between the users and providing countries. Countries party to the Protocol appoint National Focal Points (NFP) to provide information and indicate responsibilities and Competent National Authorities (CNA) to implement the Protocol. CABI has implemented an Access and Benefit Sharing (ABS) Policy and is following best practice to ensure it meets its commitments in benefit sharing. The CABI Development Fund began supporting a project in January 2015 with the goal to meet country requirements for accessing and use of genetic resources. It has renewed funding annually to keep pace with the changing environment and keep CABI's operations compliant. Currently, CABI has aligned its best practices as a user of genetic resources with its host countries' requirements and is negotiating access agreements with all provider countries to ensure that it complies not only locally but globally with the Nagoya Protocol. This process continues, $C A B I$ 's project initiation process includes an $A B S$ requirement assessment and regular checks on compliance are carried out for all active projects. This working paper has been prepared to meet CABI's commitment to inform provider countries of the benefits it has shared with them in return for the genetic resources used in research to deliver its mission.

In its work, $\mathrm{CABI}$ accesses genetic material and undertakes sampling and collection for:

- diagnosis and identification of pests and diseases, so that appropriate management recommendations can be made;

- rapid identification of newly introduced alien species to facilitate containment and management; $\mathrm{CABI}$ is aware of sensitive issues around finding new pests, invasive pathogens and work with national authorities on such issues;

- studies to assess impact of land use and climate change on biodiversity and ecosystem services which often involves finding species new to science;

- developing microbial solutions to improve health and nutrition security;

- combatting threats to livelihoods, agriculture and the environment from pests and diseases;

- developing biological control agents for the management of invasive species, reduction of crop losses and minimization of unnecessary pesticide use; and

- increasing and improving access to agricultural and environmental scientific knowledge.

$C A B I$ member countries have agreed that $C A B I$ shares the benefits of its work with genetic resources through its mission-based objectives. Benefits shared include:

- sharing of R\&D results relevant to country needs;

- collaboration in education, training, research, development programmes and individual training;

- joint authorship of publications and joint ownership of intellectual property rights;

- access to ex situ facilities and to databases;

- transfer of scientific information, knowledge and technology; and

- institutional capacity-development to help build or maintain local collections. 
This working paper provides an overview of CABI UK Centre projects active in 2019 that involve access to genetic resources and presents the findings of the assessment of benefits shared with project partners in provider countries. Of 200 projects involving genetic resources, the majority with partners in the provider countries and often with joint funding, fewer than 20 were in countries with Nagoya legislation that required compliance with ABS law. Details of 27 projects (Table 1), selected as examples to demonstrate the variety of activities are provided in this working paper, the majority of the 116 projects assessed were out of scope of Nagoya legislation. Table 1 provides the donor, the genetic resources studied, how these are used, the provider country, the country in which work is carried out, the ABS requirement and the benefits being shared. These projects include genetic resources from 22 countries: Argentina; Australia; Brazil; Canada; Chile; China; Colombia; Gabon; Germany; Ghana; India; Japan; Kenya; Madagascar; Nepal; New Zealand; Pakistan; Paraguay; the Netherlands; Trinidad and Tobago; UK; and Zambia. Of these countries 17 are party to the Nagoya Protocol but only nine have law implementing it, the remaining countries are not party, yet CABI shares benefits with all, complying with law but also with the spirit of the Convention on Biological Diversity (CBD).

Information is also provided on deposits made into CABI's living collection which holds 28,000 strains of fungi and 2000 strains of bacteria collected from over 140 countries, over $50 \%$ from CABI's member countries. Over 23,000 of these strains were collected pre-CBD with only 281 strains from 26 countries outside the UK being deposited in the collection since the Nagoya Protocol became effective on 12 October 2014. Any terms or conditions on use are recorded and these govern the future use of the particular genetic resource. 


\section{Introduction}

The 29 October 2020 marked the 10-year anniversary of the adoption of the Nagoya Protocol in Nagoya, Japan (CBD 2020a). Befittingly, CABI has reviewed steps taken to comply with and support the conservation and sustainable use of biodiversity, and in particular, the benefits it has shared arising from the use of genetic resources. CABI is dedicated to supporting sustainable economic development through agriculture and meeting the increasing global demand for quality food by improving smallholder farmers' access to markets. It works to mitigate climate change, focusing on climate-resilient food production and nutrition, utilizing and conserving a healthy landscape and properly functioning ecosystems. In fulfilling these challenges, CABI wishes to create a world in which women, young people and marginalized communities are included and treated equally in agricultural production, thus reducing youth unemployment and poverty. Helping people get access to sufficient, safe and nutritious food is a priority. Researching ways of producing and trading more food with reduced harmful pesticide inputs, reduced losses but enhanced nutritional value are key principles in $C A B I$ 's work. $C A B I$ also has a remit to protect biodiversity, helping to safeguard its survival through management of invasive species: for example invasive plants such as Mysore raspberry (Rubus niveus) which threatens rare endemic Scalesia forests in the Galapagos (Renteria et al. 2012) and Madagascar rubbervine (Cryptostegia madagascariensis) smothering the iconic Carnaúba palm and threatening the habitat of the three-banded armadillo in north-eastern Brazil (CABI 2021a). CABI is also working with CHAP (Crop Health and Protection), Russell Bio Solutions Ltd and H\&T Bioseed, to try and find a more environmentally sustainable alternative to the now banned neonic insecticides to fight the devastating cabbage stem flea beetle, Psylliodes chrysocephalus (CABI 2021b).

As countries continue to ratify the Nagoya Protocol, enact law and implement process, CABI must continue to work in compliance with the Nagoya Protocol on Access and Benefit Sharing (ABS). CABI has published its policy on ABS online under its Environmental Policies (2018a) and has designed best practice to implement them (Smith et al. 2018). Through this working paper CABI UK reports on the benefits it shares in return for access to and use of genetic resources in its research to deliver its mission to improve people's lives worldwide by providing information and applying expertise to solve problems in agriculture and the environment.

CABI's ABS policy was accepted in principle by representatives of its 48 member countries (now 50 ), at its 19th Review Conference held in the UK in July 2016, on the condition that CABI would seek appropriate national agreements. CABI makes a commitment to use genetic resources in compliance with provider country requirements and undertakes that it will deliver benefits arising from its work with these resources to these countries. CABI is looking for a less burdensome negotiation process for access by seeking provider country approval (primarily its member countries) to allow its scientists to access the resources it needs in its work (mainly invertebrates, insects and microorganisms) without having to negotiate the terms and conditions of use each time such access is required. CABI has welcomed country positions that allow multi access under projects or programmes of work. Such agreements have been reached in Ghana, for example, through a memorandum of understanding (MoU) with the CNA and in India, with an MoU and work programme with the Indian Council of Agricultural Research (ICAR). This aims to reduce the administrative burden for both CABI and the provider country. Access excludes resources covered by the International Treaty on Plant Genetic Resources for Food and Agriculture (ITPGRFA) or other overriding international conventions and is compliant with provider country national law. CABI has undertaken not to exploit genetic resources for monetary gain without involving the provider country; for example direct contact with the NFP or 
the CNA. CABI undertakes to be transparent in all its uses, regularly reporting what materials $\mathrm{CABI}$ holds for each country and what use they are being put to.

To inform staff of their responsibilities under its policy, CABI developed best practices that are appropriately modified to meet the national requirements of each of its research-centre host countries. An overview of these best practices was published (Smith et al. 2018) and in April 2020, the $C A B I A B S$ Best Practices for the Centre in Switzerland were officially recognized by the Bundesamt für Umwelt (BAFU - the Swiss Federal Office for the Environment). The status of CABI's compliance in its host countries is as follows:

- Brazil: Country-specific CABI Best Practice drafted and all work undertaken with Brazilian partners, coordinated through the CABI office in São Paulo, with all CABI researchers registered as foreign researchers;

- China: Interim agreement until national regulation in place and country-specific CABI Best Practice drafted;

- Ghana: MoU in place including CABI country-specific ABS Best Practice;

- India: National Biodiversity Authority (NBA) and ICAR routes for compliant access in place along with country-specific CABI Best Practice drafted;

- Kenya: Country-specific CABI Best Practice drafted;

- Malaysia: Country-specific CABI Best Practice drafted;

- Pakistan: Country-specific CABI Best Practice drafted;

- Switzerland: Country-specific CABI Best Practice recognized by national authority (BAFU);

- Trinidad and Tobago: Country-specific CABI Best Practice drafted;

- UK: Country-specific CABI Best Practice ready for submission when post-Brexit process is in place; and

- Zambia: Country-specific CABI Best Practice based on Kenya draft version.

Since the Nagoya Protocol was enacted in 2014, CABI has initiated over 200 projects involving genetic resources at its Egham site in the UK, the majority with partners in the provider countries and often with joint funding. Examples of these are listed in Table 1. Many have resulted in publications and shared knowledge, however, fewer than 20 were in countries with Nagoya legislation and required compliance with $A B S$ law. CABI has taken a position that it shares benefits, in the spirit of the CBD, whether or not the provider country is party to the Nagoya Protocol or has regulation in place. $C A B I$ member countries have agreed that CABI shares the benefits of its work with genetic resources through its mission-based objectives. Benefits shared include:

- sharing of R\&D results relevant to country needs;

- collaboration in education, training, research, development programmes and individual training;

- joint authorship of publications and joint ownership of intellectual property rights;

- access to ex situ facilities and to databases;

- transfer of scientific information, knowledge and technology; and

- institutional capacity development to help build or maintain local collections. 
Table 1. Twenty-seven of CABI's active projects in 2019 and the benefits shared with genetic resource provider countries.

\begin{tabular}{|c|c|c|c|c|c|c|c|}
\hline Project name & Donor & $\begin{array}{l}\text { Genetic resources } \\
\text { (organisms) } \\
\text { included }\end{array}$ & $\begin{array}{l}\text { How is the } \\
\text { organism used }\end{array}$ & $\begin{array}{l}\text { Provider } \\
\text { country(s) }\end{array}$ & $\begin{array}{l}\text { Country(s) in } \\
\text { which work is } \\
\text { carried out }\end{array}$ & ABS requirement & $\begin{array}{l}\text { Benefits being shared (monetary } \\
\text { and non-monetary) }\end{array}$ \\
\hline $\begin{array}{l}\text { Enhancing diversity } \\
\text { to overcome } \\
\text { resistance } \\
\text { evolution } \\
\text { (ENDORSE) }\end{array}$ & Newton & $\begin{array}{l}\text { Ten fungi: } \\
\text { Metarhizium or } \\
\text { Beauveria spp. }\end{array}$ & $\begin{array}{l}\text { Bulk spore } \\
\text { production }\end{array}$ & $\begin{array}{l}\text { Brazil } \\
\text { USA }\end{array}$ & UK & $\begin{array}{l}\text { The work } \mathrm{CABI} \text { is doing } \\
\text { does not trigger the UK } \\
\text { regulation }\end{array}$ & $\begin{array}{l}\text { The biopesticide product will be } \\
\text { owned by the Brazilian partners } \\
\text { benefiting from CABI's know-how } \\
\text { and sharing technology }\end{array}$ \\
\hline Coffee berry borer & $\begin{array}{l}\text { Technology Strategy } \\
\text { Board - Innovate }\end{array}$ & Beauveria bassiana & $\begin{array}{l}\text { Biopesticide; } \\
\text { strain } \\
\text { characterization }\end{array}$ & $\begin{array}{l}\text { Colombia } \\
\text { commercial } \\
\text { product }\end{array}$ & Colombia & $\begin{array}{l}\text { Joint ownership; if work } \\
\text { transfers to the UK a } \\
\text { due diligence } \\
\text { declaration is required }\end{array}$ & $\begin{array}{l}\text { Colombia: commercial product for } \\
\text { ownership and sale in Colombia }\end{array}$ \\
\hline $\begin{array}{l}\text { Colombian Cocoa } \\
\text { Control System } \\
\text { (COLCO) }\end{array}$ & $\begin{array}{l}\text { Catapult Satellite } \\
\text { Applications }\end{array}$ & Cocoa pathogens & $\begin{array}{l}\text { Cocoa plant } \\
\text { material to isolate } \\
\text { causal disease. } \\
\text { Identification } \\
\text { done through } \\
\text { Plantwise } \\
\text { Diagnostic Advice } \\
\text { and Services lab }\end{array}$ & Colombia & UK & $\begin{array}{l}\text { The work } \mathrm{CABI} \text { is doing } \\
\text { does not trigger the UK } \\
\text { regulation }\end{array}$ & $\begin{array}{l}\text { Partners benefit from data generated } \\
\text { and project outcomes }\end{array}$ \\
\hline $\begin{array}{l}\text { Improving } \\
\text { integrated pest } \\
\text { management in } \\
\text { strawberry }\end{array}$ & $\begin{array}{l}\text { Agricultural and } \\
\text { Horticultural } \\
\text { Development Board }\end{array}$ & $\begin{array}{l}\text { Commercially } \\
\text { available products }\end{array}$ & $\begin{array}{l}\text { As described on } \\
\text { the label }\end{array}$ & $\begin{array}{l}\text { Direct from } \\
\text { FARGRO }\end{array}$ & UK & $\begin{array}{l}\text { The product sample } \\
\text { was provided by } \\
\text { FARGRO, the licence } \\
\text { holder for the product }\end{array}$ & $\begin{array}{l}\text { FARGRO holds the licence with the } \\
\text { provider country with benefit sharing } \\
\text { incorporated }\end{array}$ \\
\hline $\begin{array}{l}\text { Improved freeze } \\
\text { drying of } \\
\text { entomopathogenic } \\
\text { fungi }\end{array}$ & $\begin{array}{l}\text { Technology Strategy } \\
\text { Board }\end{array}$ & $\begin{array}{l}\text { Metarhzium } \\
\text { acridum, Beauveria } \\
\text { bassiana and two } \\
\text { strains of Hirsutella } \\
\text { thompsonii }\end{array}$ & $\begin{array}{l}\text { Testing for a } \\
\text { potential freeze- } \\
\text { dried product for } \\
\text { multiple markets }\end{array}$ & Various & $\begin{array}{l}\text { UK } \\
\text { Ghana }\end{array}$ & $\begin{array}{l}\text { Technology } \\
\text { improvement, no } \\
\text { utilization }\end{array}$ & Improved product for the market \\
\hline $\begin{array}{l}\text { Scoping analysis in } \\
\text { Gabon }\end{array}$ & Olam International & $\begin{array}{l}\text { Microbial } \\
\text { communities }\end{array}$ & Observed & Gabon & Gabon & $\begin{array}{l}\text { No legislative, } \\
\text { administrative or policy } \\
\text { measures on ABS; no } \\
\text { utilization }\end{array}$ & Improved products on the market \\
\hline
\end{tabular}




\begin{tabular}{|c|c|c|c|c|c|c|c|}
\hline Project name & Donor & $\begin{array}{l}\text { Genetic resources } \\
\text { (organisms) } \\
\text { included }\end{array}$ & $\begin{array}{l}\text { How is the } \\
\text { organism used }\end{array}$ & $\begin{array}{l}\text { Provider } \\
\text { country(s) }\end{array}$ & $\begin{array}{l}\text { Country(s) in } \\
\text { which work is } \\
\text { carried out }\end{array}$ & $A B S$ requirement & $\begin{array}{l}\text { Benefits being shared (monetary } \\
\text { and non-monetary) }\end{array}$ \\
\hline $\begin{array}{l}\text { Unmanned aerial } \\
\text { vehicle } \\
\text { observations in } \\
\text { China }\end{array}$ & $\begin{array}{l}\text { Technology Strategy } \\
\text { Board - Innovate }\end{array}$ & $\begin{array}{l}\text { Metarhizium } \\
\text { acridum }\end{array}$ & Biopesticide & China & China & $\begin{array}{l}\text { Organisms originate } \\
\text { from and are used in } \\
\text { China }\end{array}$ & $\begin{array}{l}\text { Sharing knowledge and technology } \\
\text { with partners in China, the product } \\
\text { will be owned by China and used } \\
\text { there }\end{array}$ \\
\hline $\begin{array}{l}\text { Masters of } \\
\text { Advanced Studies } \\
\text { and Diploma of } \\
\text { Advanced Studies } \\
\text { in Integrated Crop } \\
\text { Management }\end{array}$ & $\begin{array}{l}\text { Swiss Agency for } \\
\text { Development and } \\
\text { Cooperation (SDC) }\end{array}$ & $\begin{array}{l}\text { Cultures from CABI } \\
\text { collection }\end{array}$ & $\begin{array}{l}\text { For training } \\
\text { purposes }\end{array}$ & Europe & Switzerland & $\begin{array}{l}\text { No utilization of } \\
\text { organisms }\end{array}$ & Participants in courses trained \\
\hline $\begin{array}{l}\text { Pest risk } \\
\text { information service } \\
\text { (PRISE) }\end{array}$ & $\begin{array}{l}\text { Plantwise; UK Space } \\
\text { Agency }\end{array}$ & Pest species & $\begin{array}{l}\text { To identify pest } \\
\text { species and } \\
\text { observation }\end{array}$ & $\begin{array}{l}\text { Ghana } \\
\text { Kenya } \\
\text { Zambia }\end{array}$ & UK & $\begin{array}{l}\text { No utilization of } \\
\text { organisms }\end{array}$ & Project outcomes shared \\
\hline $\begin{array}{l}\text { Biological control } \\
\text { of Crassula helmsii }\end{array}$ & $\begin{array}{l}\text { Department for } \\
\text { Environment, Food and } \\
\text { Rural Affairs (Defra), } \\
\text { Natural England, the } \\
\text { Ministry of Defence UK } \\
\text { and UK waterboards }\end{array}$ & $\begin{array}{l}\text { Eriophyid mite, } \\
\text { Aculus crassulae }\end{array}$ & $\begin{array}{l}\text { Research for the } \\
\text { biocontrol of } C \text {. } \\
\text { helmsii }\end{array}$ & Australia & UK & $\begin{array}{l}\text { Not a party to the } \\
\text { Nagoya Protocol }\end{array}$ & $\begin{array}{l}\text { The export permit requires } \\
\text { publication of outputs in the } \\
\text { providing country. Project report } \\
\text { publicly available on Defra website, } \\
\text { publication in conference } \\
\text { proceedings and presentations at } \\
\text { conferences }\end{array}$ \\
\hline $\begin{array}{l}\text { Biological control } \\
\text { of Japanese } \\
\text { knotweed using a } \\
\text { psyllid }\end{array}$ & $\begin{array}{l}\text { Defra, Welsh } \\
\text { Government, } \\
\text { Environment Agency, } \\
\text { British Waterways, } \\
\text { Network Rail, Cornwall } \\
\text { Council, Regional } \\
\text { Development Agency of } \\
\text { South West England, } \\
\text { United States } \\
\text { Department of } \\
\text { Agriculture (USDA), } \\
\text { British Columbia (BC) } \\
\text { Canada, Dutch }\end{array}$ & $\begin{array}{l}\text { Psyllid Aphalara } \\
\text { itadori and test } \\
\text { plants (e.g. Fallopia } \\
\text { cillinoides, Fallopia } \\
\text { sachalinensis and } \\
\text { Fagopyrum } \\
\text { esculentum) }\end{array}$ & $\begin{array}{l}\text { Identification and } \\
\text { preliminary } \\
\text { testing of many } \\
\text { species of natural } \\
\text { enemy for } \\
\text { biological control } \\
\text { of Japanese } \\
\text { knotweed }\end{array}$ & $\begin{array}{l}\text { Japan } \\
\text { Canada } \\
\text { USA } \\
\text { Netherlands }\end{array}$ & $\begin{array}{l}\text { UK } \\
\text { Canada } \\
\text { Netherlands }\end{array}$ & No access controls & $\begin{array}{l}\text { Many research outputs published, } \\
\text { numerous studentships completed, } \\
\text { and project work in Japan funded. } \\
\text { Project report publicly available on } \\
\text { Defra website }\end{array}$ \\
\hline
\end{tabular}




\begin{tabular}{|c|c|c|c|c|c|c|c|}
\hline Project name & Donor & $\begin{array}{l}\text { Genetic resources } \\
\text { (organisms) } \\
\text { included }\end{array}$ & $\begin{array}{l}\text { How is the } \\
\text { organism used }\end{array}$ & $\begin{array}{l}\text { Provider } \\
\text { country(s) }\end{array}$ & $\begin{array}{l}\text { Country(s) in } \\
\text { which work is } \\
\text { carried out }\end{array}$ & $A B S$ requirement & $\begin{array}{l}\text { Benefits being shared (monetary } \\
\text { and non-monetary) }\end{array}$ \\
\hline & $\begin{array}{l}\text { waterboards and other } \\
\text { Dutch authorities }\end{array}$ & & & & & & \\
\hline $\begin{array}{l}\text { Biocontrol of } \\
\text { Japanese knotweed } \\
\text { using leafspot } \\
\text { pathogen }\end{array}$ & $\begin{array}{l}\text { Knotweed consortium, } \\
\text { Defra, Environment } \\
\text { Agency, British } \\
\text { Waterways, Network } \\
\text { Rail, Cornwall Council, } \\
\text { Regional Development } \\
\text { Agency of South West } \\
\text { England, Welsh } \\
\text { Government, USDA, BC } \\
\text { Canada, Dutch } \\
\text { waterboards and other } \\
\text { Dutch authorities }\end{array}$ & $\begin{array}{l}\text { Fungal leafspot } \\
\text { Mycosphaerella } \\
\text { polygoni-cuspidati, } \\
\text { a range of plant } \\
\text { species closely } \\
\text { related to Fallopia } \\
\text { japonica including } \\
\text { hybrids (e.g. species } \\
\text { in the genera } \\
\text { Fallopia, Fagoyrum, } \\
\text { Polygonum) }\end{array}$ & $\begin{array}{l}\text { Research into } \\
\text { potential as a } \\
\text { classical } \\
\text { biocontrol agent } \\
\text { and subsequently } \\
\text { 'proof-of-concept' } \\
\text { research for a } \\
\text { potential } \\
\text { mycoherbicide }\end{array}$ & Japan & $\begin{array}{l}\text { UK } \\
\text { Japan } \\
\text { Netherlans } \\
\text { Canada } \\
\text { First phase of } \\
\text { the project ran } \\
\text { from } 2000 \text { to } \\
2008 \text { with the } \\
\text { exploratory } \\
\text { phase in Japan } \\
\text { and the testing } \\
\text { in the UK }\end{array}$ & No access controls & $\begin{array}{l}\text { EVID } 4 \text { report publicly available on } \\
\text { Defra website, publications in peer- } \\
\text { reviewed scientific journals and in } \\
\text { conference proceedings; conference } \\
\text { presentations; PhD study supported }\end{array}$ \\
\hline $\begin{array}{l}\text { Himalayan balsam } \\
\text { rust releases and } \\
\text { community } \\
\text { consequences of } \\
\text { introducing a } \\
\text { biological control } \\
\text { agent }\end{array}$ & $\begin{array}{l}\text { Defra, Welsh } \\
\text { government, UK } \\
\text { waterboards, local } \\
\text { action groups, local } \\
\text { governments in the UK, } \\
\text { BC Canada, BC Ministry } \\
\text { of Forests and Range, } \\
\text { Natural Environment } \\
\text { Research Council } \\
\text { (NERC), Environment } \\
\text { Agency }\end{array}$ & $\begin{array}{l}\text { Rust fungus } \\
\text { Puccinia komarovii } \\
\text { var. glanduliferae } \\
\text { and test plants (e.g. } \\
\text { Canadian Impatiens } \\
\text { glandulifera) }\end{array}$ & $\begin{array}{l}\text { Biological control } \\
\text { of Himalayan } \\
\text { balsam }\end{array}$ & $\begin{array}{l}\text { Pakistan } \\
\text { India }\end{array}$ & UK & $\begin{array}{l}\text { CABI-ICAR MoU and } \\
\text { collaboration under } \\
\text { workplan endorsed by } \\
\text { DARE and regular NBA } \\
\text { notification. MTAs and } \\
\text { voucher deposition }\end{array}$ & $\begin{array}{l}\text { Research outputs published, training } \\
\text { provided to in-country collaborators, } \\
\text { payments made for collaboration, } \\
\text { project report publicly available on } \\
\text { Defra website, publication in } \\
\text { conference proceedings and } \\
\text { presentations at conferences }\end{array}$ \\
\hline $\begin{array}{l}\text { Himalayan balsam } \\
\text { molecular analysis }\end{array}$ & Natural England & $\begin{array}{l}\text { Leaf material of } \\
\text { invasive weed } \\
\text { Impatiens } \\
\text { glandulifera }\end{array}$ & $\begin{array}{l}\text { For molecular } \\
\text { analysis }\end{array}$ & $\begin{array}{l}\text { UK } \\
\text { Canada } \\
\text { and historic } \\
\text { herbarium } \\
\text { specimens } \\
\text { from India } \\
\text { and } \\
\text { Pakistan }\end{array}$ & UK & $\begin{array}{l}\text { CABI-ICAR MoU and } \\
\text { collaboration under } \\
\text { workplan endorsed by } \\
\text { DARE and regular NBA } \\
\text { notification. MTAs and } \\
\text { voucher deposition }\end{array}$ & Research outputs published \\
\hline
\end{tabular}




\begin{tabular}{|c|c|c|c|c|c|c|c|}
\hline Project name & Donor & $\begin{array}{l}\text { Genetic resources } \\
\text { (organisms) } \\
\text { included }\end{array}$ & $\begin{array}{l}\text { How is the } \\
\text { organism used }\end{array}$ & $\begin{array}{l}\text { Provider } \\
\text { country(s) }\end{array}$ & $\begin{array}{l}\text { Country(s) in } \\
\text { which work is } \\
\text { carried out }\end{array}$ & ABS requirement & $\begin{array}{l}\text { Benefits being shared (monetary } \\
\text { and non-monetary) }\end{array}$ \\
\hline $\begin{array}{l}\text { Biocontrol of } \\
\text { Hydrocotyle } \\
\text { ranunculoides }\end{array}$ & Defra & $\begin{array}{l}\text { Listronotus } \\
\text { elongatus weevil }\end{array}$ & $\begin{array}{l}\text { Research for } \\
\text { biocontrol }\end{array}$ & $\begin{array}{l}\text { Argentina } \\
\text { Paraguay }\end{array}$ & $\begin{array}{l}\text { UK } \\
\text { Argentina }\end{array}$ & $\begin{array}{l}\text { Export of weevils from } \\
\text { Argentina and Paraguay } \\
\text { permitted in } 2014 \text { and } \\
2019, \text { respectively. } \\
\text { Results used for release } \\
\text { approval request for } \\
\text { the UK. MTA signed } \\
\text { between FuEDEI, CABI } \\
\text { and Paraguayan } \\
\text { Research Institute } \\
\text { (Fundación Moisés } \\
\text { Bertoni - FMB) }\end{array}$ & $\begin{array}{l}\text { Research outputs shared; } \\
\text { publications }\end{array}$ \\
\hline $\begin{array}{l}\text { Evaluation of a } \\
\text { white smut fungus } \\
\text { for biocontrol of } \\
\text { flowering rush } \\
\text { (Butomus } \\
\text { umbellatus) }\end{array}$ & $\begin{array}{l}\text { Consortium of different } \\
\text { North American donors }\end{array}$ & $\begin{array}{l}\text { White smut fungus, } \\
\text { Doassansia niesslii }\end{array}$ & $\begin{array}{l}\text { Research for } \\
\text { biocontrol }\end{array}$ & Germany & UK & No access controls & Report available online \\
\hline $\begin{array}{l}\text { Evaluation of a rust } \\
\text { pathogen for } \\
\text { control of Jatropha } \\
\text { gossypiifolia in } \\
\text { Australia }\end{array}$ & $\begin{array}{l}\text { Department of } \\
\text { Agriculture and } \\
\text { Fisheries, Queensland, } \\
\text { Australia }\end{array}$ & $\begin{array}{l}\text { Rust pathogen } \\
\text { Phakopsora } \\
\text { jatrophicola and } \\
\text { Australian native } \\
\text { non-target plant } \\
\text { species }\end{array}$ & $\begin{array}{l}\text { Research for } \\
\text { biocontrol }\end{array}$ & $\begin{array}{l}\text { Trinidad } \\
\text { and Tobago }\end{array}$ & $\begin{array}{l}\text { UK } \\
\text { Trinidad and } \\
\text { Tobago } \\
\text { Mexico }\end{array}$ & $\begin{array}{l}\text { Export permits for the } \\
\text { rust from Trinidad and } \\
\text { Tobago as well as } \\
\text { approval to import } \\
\text { Australian non-target } \\
\text { species for the field } \\
\text { host range testing in } \\
\text { Trinidad from the } \\
\text { relevant authorities } \\
\text { were in place }\end{array}$ & $\begin{array}{l}\text { Research outputs shared, scientific } \\
\text { papers and presentations }\end{array}$ \\
\hline $\begin{array}{l}\text { Biocontrol of } \\
\text { Hedychium } \\
\text { gardnerianum for } \\
\text { Hawaii and New } \\
\text { Zealand }\end{array}$ & $\begin{array}{l}\text { Landcare Research; } \\
\text { USDA Forest Service, } \\
\text { Hawai'i Invasive Species } \\
\text { Council (HISC); } \\
\text { Hawaiian Government; } \\
\text { Hawai'i Association of }\end{array}$ & $\begin{array}{l}\text { Merochlorops } \\
\text { dimorphus, } \\
\text { Metaprodioctes } \\
\text { trilineata }\end{array}$ & $\begin{array}{l}\text { Research for } \\
\text { biocontrol }\end{array}$ & India & UK & $\begin{array}{l}\text { CABI-ICAR MoU and } \\
\text { collaboration under } \\
\text { workplan endorsed by } \\
\text { DARE and regular NBA } \\
\text { notification. MTAs and } \\
\text { voucher deposition; } \\
\text { MoU with Sikkim }\end{array}$ & $\begin{array}{l}\text { Research outputs shared; joint } \\
\text { publications, scientific presentations } \\
\text { and training visits facilitated. Any } \\
\text { agent third party release will be } \\
\text { subject to agreement with ICAR and } \\
\text { application to NBA }\end{array}$ \\
\hline
\end{tabular}




\begin{tabular}{|c|c|c|c|c|c|c|c|}
\hline Project name & Donor & $\begin{array}{l}\text { Genetic resources } \\
\text { (organisms) } \\
\text { included }\end{array}$ & $\begin{array}{l}\text { How is the } \\
\text { organism used }\end{array}$ & $\begin{array}{l}\text { Provider } \\
\text { country(s) }\end{array}$ & $\begin{array}{l}\text { Country(s) in } \\
\text { which work is } \\
\text { carried out }\end{array}$ & $A B S$ requirement & $\begin{array}{l}\text { Benefits being shared (monetary } \\
\text { and non-monetary) }\end{array}$ \\
\hline & $\begin{array}{l}\text { Watershed } \\
\text { Partnerships (HAWP) }\end{array}$ & & & & & $\begin{array}{l}\text { University and permits } \\
\text { Through the } \\
\text { Government of Sikkim }\end{array}$ & \\
\hline $\begin{array}{l}\text { Éléphant Vert } \\
\text { Green Muscle }\end{array}$ & $\begin{array}{l}\text { Department for } \\
\text { International } \\
\text { Development (DFID), } \\
\text { Swiss Agency for } \\
\text { Development and } \\
\text { Cooperation (SDC) and } \\
\text { Directorate-General for } \\
\text { International } \\
\text { Cooperation (DGIS) }\end{array}$ & $\begin{array}{l}\text { Metarhizium } \\
\text { acridum }\end{array}$ & $\begin{array}{l}\text { Green Muscle } \\
\text { sales }\end{array}$ & $\begin{array}{l}\text { Various } \\
\text { (pre-CBD) }\end{array}$ & Niger & $\begin{array}{l}\text { Pre-CBD collected } \\
\text { strains }\end{array}$ & Not applicable \\
\hline $\begin{array}{l}\text { Clematis host range } \\
\text { testing }\end{array}$ & Landcare Research & $\begin{array}{l}\text { Insect biocontrol } \\
\text { agents and New } \\
\text { Zealand native } \\
\text { clematis samples } \\
\text { were sent to UK }\end{array}$ & $\begin{array}{l}\text { Plants imported } \\
\text { to UK for host } \\
\text { range testing and } \\
\text { insects sent to } \\
\text { New Zealand }\end{array}$ & $\begin{array}{l}\text { New } \\
\text { Zealand } \\
\text { UK }\end{array}$ & $\begin{array}{l}\text { UK } \\
\text { New Zealand }\end{array}$ & $\begin{array}{l}\text { NZ is not a party to the } \\
\text { Nagoya Protocol and } \\
\text { has no legislative, } \\
\text { administrative or policy } \\
\text { measures cited on the } \\
\text { ABS Clearing House } \\
\text { (ABSCH). No access } \\
\text { controls in UK }\end{array}$ & Not applicable \\
\hline $\begin{array}{l}\text { Biological control } \\
\text { of Rubus ellipticus } \\
\text { and } R . \text { niveus on } \\
\text { Hawaii }\end{array}$ & $\begin{array}{l}\text { USDA Hawaii Invasive } \\
\text { Species Council (HISC) } \\
\text { through USDA Forest } \\
\text { Service, and Hawai'i } \\
\text { Association of } \\
\text { Watershed } \\
\text { Partnerships (HAWP) }\end{array}$ & $\begin{array}{l}\text { Fungal pathogens } \\
\text { and arthropods; } \\
\text { Seeds of } R \text {. } \\
\text { ellipticus, } R \text {. niveus, } \\
R \text {. hawaiiensis and } \\
R \text {. argutus sourced } \\
\text { from Hawaii }\end{array}$ & $\begin{array}{l}\text { Research for } \\
\text { biocontrol }\end{array}$ & $\begin{array}{l}\text { India } \\
\text { China }\end{array}$ & $\begin{array}{l}\text { UK } \\
\text { India } \\
\text { China }\end{array}$ & $\begin{array}{l}\text { Export of natural } \\
\text { enemies under CABI- } \\
\text { ICAR workplan and } \\
\text { overarching MoU with } \\
\text { MTAs and NBA } \\
\text { notification }\end{array}$ & $\begin{array}{l}\text { Research results shared; training } \\
\text { provided. } \\
\text { Benefits for India were documented } \\
\text { in the workplans (see example case } \\
\text { studies below) }\end{array}$ \\
\hline $\begin{array}{l}\text { Control of Rubus } \\
\text { niveus on the } \\
\text { Galapagos Islands }\end{array}$ & $\begin{array}{l}\text { Fondo para el control } \\
\text { de las especies } \\
\text { invasoras de Galapagos } \\
\text { (FEIG), Charles Darwin } \\
\text { Foundation }\end{array}$ & $\begin{array}{l}\text { Rust pathogens in } \\
\text { the genus } \\
\text { Phragmidium as } \\
\text { well as other fungal } \\
\text { pathogens; } \\
\text { Seeds of } R \text {. niveus, } \\
\text { R. glaucus and }\end{array}$ & $\begin{array}{l}\text { Research for } \\
\text { biocontrol }\end{array}$ & $\begin{array}{l}\text { India } \\
\text { China }\end{array}$ & $\begin{array}{l}\text { Ecuador } \\
\text { (Galapagos } \\
\text { Islands) } \\
\text { India } \\
\text { China } \\
\text { UK }\end{array}$ & $\begin{array}{l}\text { Export of natural } \\
\text { enemies under CABI- } \\
\text { ICAR workplan and } \\
\text { overarching MoU with } \\
\text { MTAs and NBA } \\
\text { notification }\end{array}$ & $\begin{array}{l}\text { Benefits for India were documented } \\
\text { in the workplans (see example case } \\
\text { studies below) } \\
\text { An MoU and a collaborative research } \\
\text { contract have been signed between } \\
\text { CABI and Yunnan Academy of } \\
\text { Forestry and Grassland (YAFG), }\end{array}$ \\
\hline
\end{tabular}




\begin{tabular}{|c|c|c|c|c|c|c|c|}
\hline Project name & Donor & $\begin{array}{l}\text { Genetic resources } \\
\text { (organisms) } \\
\text { included }\end{array}$ & $\begin{array}{l}\text { How is the } \\
\text { organism used }\end{array}$ & $\begin{array}{l}\text { Provider } \\
\text { country(s) }\end{array}$ & $\begin{array}{l}\text { Country(s) in } \\
\text { which work is } \\
\text { carried out }\end{array}$ & ABS requirement & $\begin{array}{l}\text { Benefits being shared (monetary } \\
\text { and non-monetary) }\end{array}$ \\
\hline & & $\begin{array}{l}\text { other non-target } \\
\text { species from } \\
\text { Galapagos/Ecuador }\end{array}$ & & & & & $\begin{array}{l}\text { Kunming, China for the project; } \\
\text { benefits for China include monetary } \\
\text { benefits to the institute to undertake } \\
\text { collaborative research work and } \\
\text { training delivered in 2019; } \\
\text { presentations made }\end{array}$ \\
\hline $\begin{array}{l}\text { Invasive Plants } \\
\text { Nepal - NSF }\end{array}$ & Arizona State University & $\begin{array}{l}\text { Pathogens as } \\
\text { potential biocontrol } \\
\text { agents }\end{array}$ & Observation only & Nepal & Nepal & No utilization & N/A \\
\hline $\begin{array}{l}\text { Biocontrol of } \\
\text { Tutsan }\end{array}$ & Landcare Research & $\begin{array}{l}\text { Rust fungus } \\
\text { Melampsora } \\
\text { hypericorum; } \\
\text { Seeds of the plant } \\
\text { Hypericum } \\
\text { androsaemum from } \\
\text { New Zealand }\end{array}$ & $\begin{array}{l}\text { Susceptibility } \\
\text { testing of UK rust } \\
\text { against New } \\
\text { Zealand } \\
\text { populations of } \\
\text { tutsan }\end{array}$ & $\begin{array}{l}\text { UK } \\
\text { Rust and } \\
\text { seeds sent } \\
\text { from New } \\
\text { Zealand }\end{array}$ & UK & $\begin{array}{l}\text { No access controls in } \\
\text { the UK }\end{array}$ & N/A \\
\hline $\begin{array}{l}\text { Rescuing and } \\
\text { restoring the native } \\
\text { flora of Robinson } \\
\text { Crusoe Island }\end{array}$ & Defra & $\begin{array}{l}\text { Potential biocontrol } \\
\text { agents }\end{array}$ & $\begin{array}{l}\text { Research for } \\
\text { biocontrol }\end{array}$ & Chile & Chile & $\begin{array}{l}\text { Chile not a party to the } \\
\text { Nagoya Protocol; } \\
\text { Native genetic resource } \\
\text { used in provider } \\
\text { country }\end{array}$ & $\mathrm{N} / \mathrm{A}$ \\
\hline $\begin{array}{l}\text { Biological control } \\
\text { of Sagina } \\
\text { procumbens on } \\
\text { Gough Island }\end{array}$ & $\begin{array}{l}\text { Royal Society for the } \\
\text { Protection of Birds } \\
\text { (RSPB) }\end{array}$ & Fungal pathogens & $\begin{array}{l}\text { Research for } \\
\text { biocontrol }\end{array}$ & UK & $\begin{array}{l}\text { UK (overseas } \\
\text { territory of } \\
\text { Tristan da } \\
\text { Cunha) }\end{array}$ & $\begin{array}{l}\text { No provider country } \\
\text { access controls }\end{array}$ & Research outputs shared \\
\hline $\begin{array}{l}\text { Rubbervine } \\
\text { biocontrol for } \\
\text { Brazil }\end{array}$ & SC Johnson & $\begin{array}{l}\text { Rust pathogen } \\
\text { Maravalia } \\
\text { cryptostegiae }\end{array}$ & $\begin{array}{l}\text { Research for } \\
\text { biocontrol }\end{array}$ & $\begin{array}{l}\text { Madagascar } \\
\text { Kenya }\end{array}$ & UK & $\begin{array}{l}\text { Export permit in place } \\
\text { from Madagascar; rust } \\
\text { strain ex Kenya } \\
\text { collected in the late } \\
\text { 1980s, thus out of } \\
\text { scope }\end{array}$ & $\begin{array}{l}\text { Research outputs shared, training } \\
\text { given to Malagasy scientists in the } \\
\text { field during survey work conducted in } \\
2018, \text { monetary payment to the } \\
\text { collaborating university in } \\
\text { Antananarivo }\end{array}$ \\
\hline
\end{tabular}




\section{CABI UK 2019 project ABS assessment}

In 2019, CABI UK, Egham had 116 active projects that involved genetic resources. These were assessed against the UK requirements (UK 2021) including:

- The Nagoya Protocol (Compliance) Regulations 2015 (UK Statutory Instrument, No. 821) (UK 2015);

- Regulation (European Union-EU) No. 511/2014 on compliance measures for users from the Nagoya Protocol on Access to Genetic Resources and the Fair and Equitable Sharing of Benefits Arising from their Utilisation in the Union (EC 2016); and

- Implementing Regulation (EU) 2015/1866 laying down the detailed rules for the implementation of Regulation (EU) 511/2014 as regards the register of collections, monitoring user compliance and best practices (EC 2015).

The Office for Product Safety and Standards (OPSS), Department for Business, Energy \& Industrial Strategy (BEIS) is the UK regulator who is responsible for implementing and enforcing Nagoya legislation.

When considering the use of genetic resources (organisms), compliance with provider country requirements under the Nagoya Protocol must be ensured. This is in addition to checking whether other permissions are needed, for example regarding the Convention on International Trade in Endangered Species of Wild Fauna and Flora (CITES), quarantine, export licences for dangerous organisms etc. and of course land owner/protected area access. CABI's assessment was based on whether the sample access met the scope of the EU regulation. The three elements of information required for the assessment are:

1. Provenance of the genetic (biological) materials: the country they were sourced from and if access is regulated. When receiving genetic resources, they should be accompanied by a Material Transfer Agreement (MTA) indicating where the material originated from and what you can and cannot do with it.

2. The timeline of collection/anticipated collection (when isolated from in situ) to indicate if regulation was in place at the time of collection.

3. Proposed use - some actions/observations do not trigger the Nagoya Protocol - for example identification/taxonomy but this ultimately depends on the provider country process requirements.

The first port of call should be the ABS Clearing House (ABSCH), where the status and source country requirements can be found in the country profile. The country status regarding the Nagoya Protocol and if it has ABS measures will be stated, and if not, it is advisable to check if the country is party to the CBD. The data on the ABSCH is not always up to date so when there is no information on status it is wise to check with the national authorities, the national focal point or the relevant CNA. If the country has no ABS measures, no further action is required, other than ensuring other permissions, for example regarding plant health etc. have been obtained. If the provider country is party to the Nagoya Protocol, users must find out what ABS measures are in place and when they were enacted. If the genetic material (organism) was collected before October 2014, then the Nagoya Protocol does not apply. If the collection was after that date and the country controls access, users must obtain Prior Informed Consent (PIC) and negotiate MAT before collection and use. The latter may be required by 
law enacted to implement the $C B D$, so country laws and requirements may well be in position despite a country not being party to the Nagoya Protocol. In the case of the CABI projects listed in Table 1, the genetic resources involved are from 22 countries: Argentina; Australia; Brazil; Canada; Chile; China; Colombia; Gabon; Germany; Ghana; India; Japan; Kenya; Madagascar; Nepal; New Zealand; Pakistan; Paraguay; the Netherlands; Trinidad and Tobago; UK; and Zambia. Of these countries 17 are party to the Nagoya Protocol but only nine have law implementing it. The remaining countries are not party (see Table 2), yet CABI shares benefits with all, complying with law but also with the spirit of the CBD.

Table 2. Nagoya status of the countries providing genetic resources for the 27 projects listed in Table 1.

\begin{tabular}{lll}
$\begin{array}{l}\text { Party to Nagoya Protocol with } \\
\text { law }\end{array}$ & $\begin{array}{l}\text { Party to the Nagoya Protocol } \\
\text { with no implementing law (as } \\
\text { of } 8 \text { July 2021 on the ABSCH) }\end{array}$ & Not party to the Protocol \\
\hline Brazil & Argentina & Australia \\
Colombia & Chile & Canada \\
Germany & China & New Zealand \\
India & Gabon & Paraguay \\
Japan & Ghana & Trinidad and Tobago \\
Kenya & Nepal & \\
Madagascar & Pakistan & \\
The Netherlands & Zambia & \\
UK & & \\
\hline
\end{tabular}

The Nagoya Protocol is triggered by utilization - i.e. conducting R\&D on the genetic and/or biochemical composition of genetic resources, including through the application of biotechnology. It is therefore important to determine and anticipate all potential uses of the genetic resource, to avoid subsequent negotiations for new use. If the country does not control access (such as the UK and much of the EU), applicants may collect and use the materials as they wish as long as they do not break other laws such as trespass in collecting the materials. If it is not clear whether access legislation is in place, contacting the relevant national focal point and keeping a record of the enquiry email and any response will form part of the due diligence process. The EU regulation provides compliance measures for EU users but does not address issues of access in Member States which is down to them individually. The EU regulation as applied in the UK only applies to genetic resources if:

a) They are from countries that exercise sovereign rights.

b) Countries have established access measures and ratified the Nagoya Protocol.

c) They were accessed after 12 October 2014 (or, if later, the date of enactment of national legislation).

d) They are not already governed by specialized international instruments. 
In the EU and the UK, there are two checkpoints where due diligence declarations may be required from the user. The Regulator must be informed when:

1. a research grant is received;

2. a product is about to be placed on the market.

As a result of this assessment the majority of the 116 projects were found to be out of scope of the EU regulation as implemented in the UK hence only 27 were presented here (see Table 1). Nine of the projects were internally funded and were designed to improve services and outputs to users, partners and provider countries. These included improvements to methodologies such as matrix-assisted laser desorption/ionization time-of-flight (MALDI-TOF)-based invasive plant species characterization, metagenomic analysis of soil samples and the use of MinION next generation sequencing for methodology development. These projects did not qualify as utilization and therefore did not require due diligence declarations. One of the projects that was internally funded was for the creation of a validated sequence database using publicly available sequence data enhanced with those generated from the CABI genetic resource collection. The use of Digital Sequence Information (DSI) is still under consideration by countries and discussion at the Conference of the Parties continues on the topic. This situation requires close monitoring and the ultimate decision could have severe and restrictive consequences for molecular biology and the study of biodiversity (CBD 2020b).

Twenty-four projects were funded by research programmes, institutions or organizations that provided services to provider country representatives, for example: (i) identification of organisms; (ii) diagnosis of plant disease; and (iii) assessment of contamination of seeds (e.g. oil palm intermediate quarantine checks) or products including culture supply, where only a supply charge is made and where all cultures are provided under an MTA. A benefit shared from the deposit of the strains in the collection is that the depositors have free access to their strains and can claim a free culture for their non-commercial studies. The invasive best practice solutions project funded by the Netherlands Ministry of Agriculture (LNV) involved insect identification. The Global Plant Clinic provided disease identification funded by the Department for International Development (DFID) and Swiss Agency for Development and Cooperation (SDC) for ten countries including Bangladesh, Barbados, Ethiopia, Ghana, Grenada, India, Nepal, the Americas and Trinidad and Tobago. Such work was not considered to be utilization therefore the Nagoya Protocol regulations were not triggered but the benefits shared included the diagnosis, assessment or identification provided.

Several of the projects utilized organisms from countries that have no access regulation, for example the UK, where 16 projects utilized UK genetic resources. Of these, three projects concerned the CHAP UK Crop Health Agri-Tech Innovation Centre (CHAP 2020), which involves creating a collection of UK microorganisms associated with major UK crops. Another project, Azolla Control, is the provision of a commodity, a weevil (Stenopelmus rufinasus) for the biocontrol for the invasive weed, Azolla filiculoides, growing on water surfaces in the UK; originally the weevil was an accidental introduction from the USA but has become naturalized in the UK (first detected in 1921) and is now collected from the wild, reproduced in quantity and provided for use in the UK. A number of other projects utilize UK genetic resources, sourcing biocontrol agents for the control of invasive plants and insects elsewhere. These include the control of horsetail (Equisetum arvense), tutsan (Hypericum androsaemum) and old man's beard (Clematis vitalba) in New Zealand and for control of earwigs in the Falkland Islands. One project sought to use UK genetic resources for the biocontrol of buddleia for Network Rail in the UK. See Table 1 for further examples of CABI projects and the benefits shared from their study. 


\section{CABI living collection}

$\mathrm{CABI}$ has been protecting investment in research and keeping resources for further study in its living collection which has been a vital resource for research with organisms collected since the 1920s. The collection holds 28,000 strains of fungi and 2000 strains of bacteria collected from over 140 countries, over $50 \%$ from CABI's member countries. The holdings span the introduction of chemical biocides, pollution with plastics and antimicrobials and could demonstrate impacts of climate change and development in plant pathogens adapting to improved crop varieties and developing resistance to treatments. Over 23,000 of these strains were collected pre-CBD with only 281 strains from 26 countries outside the UK being deposited in the collection since the Nagoya Protocol became effective on 12 October 2014 (Table 3). When strains from the collection are recovered for use or supply to researchers outside $\mathrm{CABI}$, restrictions, permit requirements and terms and conditions are checked and followed and the recipient or users are informed.

Table 3. Nagoya Protocol compliance measures for strain deposits in the CABI living collection after the Nagoya Protocol became effective on 12 October 2014 with country legislative status as of January 2021.

\begin{tabular}{|c|c|c|}
\hline Source country & $\begin{array}{l}\text { Current Nagoya status (28 January } \\
\text { 2021) }\end{array}$ & $\begin{array}{l}\text { ABS commitment of recipient of } \\
\text { strain }\end{array}$ \\
\hline Brazil & $\begin{array}{l}\text { Not a party but signatory with } A B S \\
\text { legislative measures }\end{array}$ & $\begin{array}{l}\text { Notify authorities and share } \\
\text { benefits if a product using the } \\
\text { organisms goes to market }\end{array}$ \\
\hline Burundi & Party with legislative measures & Share benefits as specified in MAT \\
\hline Canada & Not a party and no legislative measures & None \\
\hline Columbia & $\begin{array}{l}\text { Not a party but signatory with } A B S \\
\text { legislative measures }\end{array}$ & $\begin{array}{l}\text { Share benefits according to country } \\
\text { requirements }\end{array}$ \\
\hline Ethiopia & Party with legislative measures & Share benefits as specified in MAT \\
\hline France & Party with legislative measures & $\begin{array}{l}\text { Share benefits according to country } \\
\text { requirements }\end{array}$ \\
\hline Germany & $\begin{array}{l}\text { Party with legislative measures but no } \\
\text { access controls }\end{array}$ & None \\
\hline Guinea & Party with no legislative measures & $\begin{array}{l}\text { None if sample was collected with } \\
\text { required permissions before law } \\
\text { enacted }\end{array}$ \\
\hline Honduras & Party with legislative measures & Share benefits as specified in MAT \\
\hline India & Party with legislative measures & $\begin{array}{l}\text { Share benefits according to country } \\
\text { requirements }\end{array}$ \\
\hline Jamaica & Not a party and no legislative measures & None \\
\hline Japan & Party with legislative measures & Share benefits as specified in MAT \\
\hline
\end{tabular}




\begin{tabular}{|c|c|c|}
\hline Source country & $\begin{array}{l}\text { Current Nagoya status (28 January } \\
\text { 2021) }\end{array}$ & $\begin{array}{l}\text { ABS commitment of recipient of } \\
\text { strain }\end{array}$ \\
\hline Kenya & Party with legislative measures & $\begin{array}{l}\text { Share benefits according to country } \\
\text { requirements }\end{array}$ \\
\hline Malaysia & $\begin{array}{l}\text { Party with legislative measures which } \\
\text { are not listed on the } \mathrm{ABSCH}\end{array}$ & $\begin{array}{l}\text { Share benefits according to country } \\
\text { requirements }\end{array}$ \\
\hline Mauritius & Party with no legislative measures & $\begin{array}{l}\text { None if sample collected with } \\
\text { required permissions before law } \\
\text { enacted }\end{array}$ \\
\hline Nigeria & Not a party and no legislative measures & None \\
\hline Paraguay & Not a party and no legislative measures & None \\
\hline Rwanda & Party with no legislative measures & $\begin{array}{l}\text { None if sample was collected with } \\
\text { required permissions before law } \\
\text { enacted }\end{array}$ \\
\hline South Africa & Party with legislative measures & Share benefits as specified in MAT \\
\hline Spain & Party with legislative measures & $\begin{array}{l}\text { Share benefits according to country } \\
\text { requirements }\end{array}$ \\
\hline Sudan & Party with legislative measures & Share benefits as specified in MAT \\
\hline Sweden & $\begin{array}{l}\text { Party with legislative measures but no } \\
\text { access controls }\end{array}$ & None \\
\hline Tanzania & Party with no legislative measures & $\begin{array}{l}\text { None if sample was collected with } \\
\text { required permissions before law } \\
\text { enacted }\end{array}$ \\
\hline Uganda & Party with legislative measures & $\begin{array}{l}\text { Share benefits according to country } \\
\text { requirements }\end{array}$ \\
\hline USA & Not a party and no legislative measures & None \\
\hline Zimbabwe & Party with legislative measures & Share benefits as specified in MAT \\
\hline
\end{tabular}

The strains available for distribution that were deposited after the enactment of the Nagoya Protocol in the provider country are supplied with all information that gives clarity on the Nagoya status and clarity on their use. It is critical that a collection keeps abreast of the Nagoya status of countries as this can change. Currently, there are four countries listed in Table 3 that are party to the Protocol but, at the time of writing, had no legislative measures to implement it (Guinea, Mauritius, Rwanda and Tanzania). These countries are currently drafting their measures and these will come into force in due course. Other countries such as Brazil have changed their law and process and, as another example, Malaysia, has enacted law but this is not listed on the $\mathrm{ABSCH}$. The CABI collection supplies its strains under restrictive conditions requesting the recipient not to pass strains onto third parties. This is crucial to enable tracking of where strains have moved and how they are being used, also limiting the chances of contamination, deterioration and replacement of strains. The conditions of supply are 
provided alongside CABI's online catalogue of strains (CABI 2021c). CABI's first collection catalogue issued under the Commonwealth Mycological Institute in 1953 made available strains collected almost 100 years ago, many of these strains continue to be available today, examples are shown in Table 4 .

Table 4. Entries in the CABI living collection first edition catalogue available today.

\begin{tabular}{|c|c|c|c|c|}
\hline Name & $\begin{array}{l}\text { IMI strain } \\
\text { number }\end{array}$ & $\begin{array}{l}\text { Year of } \\
\text { isolation }\end{array}$ & Country & Use \\
\hline Absidia glauca & 15405 & 1929 & UK & $\begin{array}{l}\text { Demonstrates } \\
\text { perfect (sexual) } \\
\text { with IMI } 15406\end{array}$ \\
\hline Absidia glauca & 15406 & 1929 & UK & $\begin{array}{l}\text { Demonstrates the } \\
\text { perfect (sexual) state } \\
\text { with IMI } 15405\end{array}$ \\
\hline Aspergillus alliaceus & 16125 & 1937 & USA & Taxonomy \\
\hline Aspergillus amstelodami & 17455 & 1947 & USA & Testing mould-proofing \\
\hline $\begin{array}{l}\text { Aspergillus avenaceus } \mathrm{G} . \\
\text { Smith }\end{array}$ & 16140 & 1938 & UK & Taxonomy \\
\hline Aspergillus fumigatus & 16030 & 1920 & UK & $\begin{array}{l}\text { Reference strain for } \\
\text { aspergillosis of lungs }\end{array}$ \\
\hline Aspergillus luchuensis & 15953 & $\begin{array}{l}\text { Received at } \\
\text { CABI } 1941\end{array}$ & Japan & $\begin{array}{l}\text { 'Awamori' (alcoholic } \\
\text { beverage) }\end{array}$ \\
\hline Aspergillus tamarii & 16129 & 1923 & Ghana & Fermented cocoa \\
\hline Beauveria bassiana & 12943 & 1921 & UK & Biocontrol agent \\
\hline Penicillium camemberti & 27831 & 1920 & USA & $\begin{array}{l}\text { French } \\
\text { cheese }\end{array}$ \\
\hline Penicillium commune & 39812 & 1904 & USA & Cheese contamination \\
\hline Penicillium rubens & 15378 & 1928 & UK & $\begin{array}{l}\text { Sir Alexander Fleming's } \\
\text { historical isolation }\end{array}$ \\
\hline Memnoniella echinata & 16201 & 1943 & India & Ex cotton fabric \\
\hline
\end{tabular}

aIMI, the CABI culture collection, formerly IMI-International Mycological Institute.

Providing such access to a country's biodiversity has responsibilities that recognized public service collections adhere to (Verkley et al. 2016; Smith et al. 2017). The EU Regulation No 511/2014 (implemented in the UK) is supported by the Commission Implementing Regulation (EU) 2015/1866 of 13 October 2015 which lays down detailed rules for implementation concerning the register of collections, monitoring user compliance and best practices. Registered collections and best practices can assist users in complying with their due diligence obligations. Registered collections are required to effectively apply measures resulting in the supply of genetic resources with documentation 
providing evidence of legal access including MAT governing the allowed use and requirements for benefit sharing. This is provided to assist users in complying with their obligations. Users that obtain genetic resources from a collection included in the register should be considered to have exercised due diligence with regard to the seeking of information (UK 2015). CABI UK is in the process of seeking recognition of its best practice with the UK Department for Environment, Food and Rural Affairs (Defra) and is considering becoming a registered collection.

The $C A B I$ collection provides details of any ABS commitments made when the strains supplied were accessed, providing legal clarity on use. Many strains are provided for non-commercial studies only. The key role of a collection is not just the provision of reference and production strains but the information associated to them to facilitate legal use. This includes intellectual property rights as well as MAT between collector/user and the providing country (Smith et al. 2020). The benefits provided by the collection include retention of strains to underpin published science, maintenance and provision of strains for future use and the ex situ conservation of microbial diversity.

CABI has published its policy online (CABI 2018a) and is in the process of seeking endorsement of its Centres' ABS Best Practices with the national authorities of their host countries (Smith et al. 2018; Hinz et al. 2019):

- Africa Regional Centre, Kenya;

- Africa, Ghana (MoU with Ghana CNA);

- Africa, Zambia;

- Brazil;

- China;

- India;

- Malaysia;

- Pakistan;

- Switzerland (ABS Best Practice recognized by CNA);

- Trinidad and Tobago; and

- UK.

\section{Issues impacting on CABI's compliance}

The principal impact currently is caused by the fact that CABI has 50 member countries (CABI 2021d), has a presence in 21 of these and has active research centres in 11 countries; each country responding differently to the Nagoya Protocol. Thirty-three of CABI's member countries have responded to the Nagoya Protocol, with nine having ratified it, eight signatories and 16 party to it. Additionally, CABI projects operate currently in over 70 countries (CABI 2021e). According to the ABSCH website (accessed in August 2021) 68 countries have published legislative, administrative or policy measures of the 130 parties. Many countries are in the process of assessing whether they become party and of those that are, 59 are still to publish or even consider the regulations and processes they will put in place. The added complication is that outside Nagoya many countries have biodiversity laws that implement the CBD and through this require PIC, MAT and equitable sharing of benefits. To ensure compliance, $\mathrm{CABI}$ has $\mathrm{ABS}$ Best Practices for each of its centres that reflect the host country 
requirements. This all makes negotiations for access to research material often convoluted and drawn out and can delay work and ultimately project outputs. The hope is of course that once settled (i.e. all countries have decided the process they wish to follow and accept that surveillance is in place to ensure compliant access and use) the processes will be clear, and access and agreements swifter to deliver. This should apply to both the access to genetic resources for the researcher and the fair and equitable sharing of benefits for the provider.

Regarding the continued discussions on DSI, CABI believes that amendments to the Nagoya Protocol are not necessary in respect to DSI and is happy to see it treated at a country level. It is akin to derivatives and it is clear that if accessed with the genetic resource on which it is based or generated after accessing the genetic resource, the terms on its generation and use should be covered by MAT. However, inevitably this would mean that countries will take their own position on this, potentially making international collaboration and usage difficult. To avoid this, it would be helpful to have a common agreement on the generation of DSI and how it can be used so as not to impede innovation in the life sciences.

Essentially, generating and publishing sequence data is considered by many as the production of descriptive information on the organism and therefore not utilization. As such, it should be out of the Nagoya Protocol regulatory scope. Publishing the sequence as electronic data is an act of sharing such descriptive information and thus meets any benefit-sharing commitment required. DSI can be used at many non-exploitative levels: for example, its use to confirm identification is an observation rather than research; in most cases the resulting sequence data are published.

If DSI is used for financial benefit then this should be considered utilization and the full benefit sharing aspect would be negotiated with the provider country, as would be done for access to the organism itself. Such use and its implications should be made clear on terms and conditions of use of public databases containing DSI. The generation and use of DSI must be considered when negotiating access - i.e. be expressed in the MAT and presented in any MTA to give clarification on what can and cannot be done regarding DSI (at least until clarification is given by the Conference of the Parties and reflected [if needed] in guidance or regulation).

Selected DSI such as barcodes are becoming standard tools for identification and phylogenetic characterization of species and populations. The real power of this approach becomes most obvious when sequences from multiple individuals and sources (countries) are freely shared and duly acknowledged. Whole genome sequencing will, without any doubt, have a similar impact on taxonomy (Bridge et al. 2021). We argue strongly that DSI generated for taxonomic or descriptive purposes needs to be freely shared in the public domain to help address the taxonomic impediment that the CBD recognizes, as well as to meet the needs of agriculture and other sciences. Indeed, we suggest that such generation and publishing of DSI should be considered as part of a country's responsibilities under Article 7 (Identification and Monitoring) and Article 17 (Exchange of Information) of the CBD. It is of course essential that identifications are correct and soundly based before sharing, particularly as a misidentified plant disease may have serious consequences on a country's trade prospects.

Specific to areas of CABI's work in classical biological control and the development of biopesticides requires retracing invasive species and crop pathogens back to the country of origin. There are many potential biological control agents for the 34 major invasive plants and insects in the UK, these belong to several genera of fungi including Arthrobotrys, Beauveria, Entomophthora, Metarhizium, Paecilomyces, Puccinia, Trichoderma, Verticillium (over 20 genera listed in Ainsworth and Bisby's Dictionary of the Fungi (Kirk et al. 2011)). The invasive species have over 20 countries of origin 
including Australia, Argentina, Brazil, Canada, Chile, China, India, Iran, Japan, Malaysia, Mexico, New Zealand, Paraguay, Poland, Russia, South Africa, Ukraine, Uruguay and the USA. These countries can each have a different status regarding the Nagoya Protocol (e.g. Non-party, Party with law, a Party without law and even a Non-party with law). Additionally, the national laws can differ in scope and requirements making negotiations for permissions and settling MAT for access and use extremely complicated.

Ultimately, CABI is an advocate of the CBD and welcomes measures to conserve and sustainably utilize genetic resources with associated sharing of benefits. The majority of access to genetic resources results in knowledge, which is most often shared through publications. The benefits that come from the approach to carry out research as much as possible in the country where the genetic resource is accessed are clear and fully supported by CABI. However, it is often essential, such as in the case of research on a new crop pathogen, that samples of genetic resources can be transferred to appropriate resources and where expertise is available. Some countries have made allowances for collaborative research and the sharing of non-monetary benefits for programmes of work or specific projects. It is critical that research for the public good is not hampered, for instance facilitating the identification and control of pests and diseases which could ultimately improve food security and yield.

Biological control of invasive species most often requires sourcing agents (invertebrates and pathogens) from countries of origin or where the species is established. Current thinking on the sovereign rights over invasive species and the organisms using them as a host is that they belong to the country in which they are growing naturally and where they are established, not the country where they might have originated. Draft EU General guidance (EC 2019) states that Regulation (EU) No $1143 / 2014$ does not make a distinction between alien species which are introduced to the environment intentionally and ones which result from unintentional release. It goes on to state that alien species, once established (i.e. having at least one self-sustaining population in the wild) can be seen as occurring in in situ conditions in the country where they are not native (i.e. into which they have been introduced or spread from another country where they are native or not native). Since they are established in situ they can be understood as falling under sovereign rights of the country where they are established despite also being non-native within that country. If the country has enacted access legislation applicable to such species and other conditions for applicability of the EU ABS Regulation are met, they fall in scope of the EU ABS Regulation.

In the case of CABI's classical biocontrol projects, organisms are most often sourced from the centre of origin of the target invasive in order to find co-evolved host-specific natural enemies. Where biocontrol agents are established from previous releases or through accidental introduction, it can become quite complicated when dealing with $A B S$ issues. Different countries have different views over whether biocontrol triggers benefit sharing under the Nagoya Protocol. CABI shares the benefits from its biological control work by publishing the results and making the biological control agents and, where applicable, their formulations for application available for use. These are in addition to the usual benefit sharing that includes training, joint projects, direct monetary reimbursement. CABI, along with many of its partners, believe that classical biocontrol is a common good and dependent on reciprocal and free exchange of genetic resources between countries, plus that all countries can profit and may provide and receive biocontrol agents. 


\section{Examples of some benefit sharing case studies}

ENDORSE project: Enhancing Diversity to Overcome Resistance Evolution. This collaborative project (CHAP 2020) is investigating the use of multiple fungal biopesticides across agricultural landscapes as selection for resistance varies in different locations preventing a uniform evolutionary response. In natural environments, insect species are genetically variable and few individuals have genes to resist pathogens. The project is inspired by this fact and seeks to make the agricultural landscape more diverse, so that the pressures favouring resistance evolution are temporally and spatially variable. This could allow us to use the next generation of biopesticides for many years without consistent resistance evolution.

The team will also consider the suitability of fungal biopesticides for industrial-scale production and field application in Brazil, and provide the industry with innovative solutions for crop protection, including improved delivery systems, higher pest control consistency and enhanced performance under field conditions. In addition, the study will identify the barriers preventing the uptake of these new pest control technologies and research methods to encourage farmer behavioural change. The research will also provide economic and social science data to underpin policy recommendations regarding incentive schemes, publicity campaigns and marketing strategies.

The project was initiated in 2019 when CABI joined an international team of scientists, led by the University of Stirling, to take a 'revolutionary approach' in attempting to tackle resistance to pesticides in insects with a specific focus on crop pests in Brazil. The $f 620,000$ study will see UK-based Dr Belinda Luke working on the mass production of fungal biopesticides and formulation development from CABI's laboratories in Egham, Surrey, while Dr Yelitza Colmenarez and Natália Corniani - from CABI's centre in São Paulo, Brazil - will disseminate a range of associated training activities. Pesticide resistance is a serious problem for the agriculture industry worldwide, with pests consuming between $10 \%$ and $20 \%$ of all global crops while growing or in storage. In Brazil, the agricultural economy loses approximately US\$17.7 billion ( $£ 13.6$ billion) a year to outbreaks of insects and other arthropod pests in crops. The country's agricultural sector heavily relies on widespread pesticide application, which has led to the evolution of pesticide resistance in several significant pests.

The project received ten fungal isolates from Brazil for spore mass production. Some of the isolates were Brazilian and some were originally from the USA. Of the ten isolates sent, six were suitable to be mass produced with two isolates producing a larger quantity of spores. Brazil is not a party to the Nagoya Protocol although it is a signatory, signed on 2 February 2011, and has law to regulate and enforce benefit sharing according to the requirements of the Nagoya Protocol. The USA is neither a party to the Nagoya Protocol nor a signatory.

The organisms from Brazil require access permissions to collect and send to the UK but they were provided directly from the American Type Culture Collection. Brazil requires all use of Brazilian isolates, no matter the route of supply, to be registered and benefits shared from their utilization when a product is placed on the market. In this instance, a collection in a non-signatory (non-party) country, the USA, provided the access. CABI holds the documentation provided on supply and there is a project agreement in place that deals with intellectual property but does not directly address benefit sharing under the CBD. The product (mass produced spores for use as a biopesticide) is owned by the Brazilian partners and therefore Brazil will benefit from CABI's work. The work undertaken by CABI was therefore a service and ordinarily would not trigger the EU regulation as implemented in the UK. 
The Regulation (EU) No 511/2014 of the European Parliament was adopted on 16 April 2014 and requires provider country requirements to be met only if all the conditions are met, including the sample being collected post-enactment of the Protocol, provider country national law is in place and that the genetic resource is being utilized. In this case, Brazil has law but is not party to the Nagoya Protocol and the growth and biomass production did not constitute utilization. Under normal circumstances benefit sharing would not have been required under EU regulation, however, under Brazilian law it would be if CABI owned and marketed the product. As ownership is Brazilian, Brazil has benefited from CABI's know-how and from CABI's access to Brazilian resources. If Brazilian genetic resources are held in collections in other countries, Brazil expects that they are only provided if recipients agree to undertake benefit sharing commitments. This is not relevant in this particular case but could be an issue in other studies. CABI considers that its principle of sharing benefits with provider countries is fully met in this instance.

Rubus ellipticus and $\boldsymbol{R}$. niveus (var. obcordatus). These are classed as one of the world's 100 worst invasive species (IUCN-International Union for Conservation of Nature) (Lowe et al. 2000). The plant was introduced to the island of Hawaii, presumably for its horticultural potential and was first collected as an escapee from cultivation in 1961 where it naturalized in the Hawai'i Volcanoes National Park (Wagner et al. 1999). A single plant can grow into a $4 \mathrm{~m}$ tall impenetrable thicket and with its recurved prickles and sturdy stems poses a problem for livestock and humans alike. In addition to invading pastures and disturbed areas, $R$. ellipticus has penetrated deeply into pristine wet forests throughout the island of Hawaii. Plants can establish in dense shade and grow to overtop adjacent hapu'u (Cibotium menziesii, Hawaiian tree fern). Longer range spread is considered inevitable and there is generally little doubt that, in time, R. ellipticus has the ability to become established throughout the Hawaiian Islands. The congener, Rubus niveus, introduced into Hawaii in the 1960s, is invasive on Hawai'i, Kauai and Maui. The ecological and economic impacts of both Rubus species are similar, and the species are now considered to be beyond management using traditional control methods.

Initial survey work was conducted in collaboration with national counterparts in the Indian part of the native Himalayan range, but ad hoc surveys were also conducted in China. Focusing primarily on natural enemies associated with $R$. ellipticus, a range of damaging arthropods and plant pathogens was recorded. The scope of the project was subsequently extended to include also $R$. niveus, which grows in close proximity to $R$. ellipticus in the field, and shares a similar suite of natural enemies. Targeting both Rubus species simultaneously reduces cost and effort because potential biocontrol agents for each weed will be screened for specificity using the same list of test plants. This research effort is co-funded by studies for R. niveus conducted by CABI for the Galapagos Islands, where this species is also invasive. As described in Table 1 the benefits from this project were that research results were shared and training in various aspects of biological control were provided.

Three 'wild gingers'. Hedychium gardnerianum (Kahili ginger), Hedychium flavescens (yellow ginger) and Hedychium coronarium (white ginger), originating from the foothills of the Himalayas, have escaped from botanical and public gardens and are now aggressively invading many forest ecosystems across the world (CABI 2018b). Most of the threatened ecosystems are on islands and these are often unique and delicate. Rare invertebrates in Brazil and the Portuguese Azores bullfinch are threatened by habitat loss, while in New Zealand and Hawaii the smothering of native young plants and the prevention of seedling establishment threatens whole ecosystem processes and endangers the biodiversity of native, undisturbed forests. CABI has been funded by a consortium of sponsors from 
New Zealand and Hawaii to find a biological control for the most invasive of the Hedychium complex, H. gardnerianum.

In India, DARE (Department of Agricultural Research and Education) provides the necessary government linkages to several autonomous bodies including the ICAR, the premier research organization for coordinating, guiding and managing research and education in the country. Under the aegis of a 3-year CABI-ICAR workplan, sanctioned by DARE and which includes access and use of genetic resources, CABI works with ICAR institutes; the National Bureau of Agricultural Insect Resources (NBAIR) and Indian Agricultural Research Institute (IARI), have facilitated export of natural enemies to the UK, under detailed MTAs, and following voucher deposition and approval by an export committee. The NBA is kept informed of the collaborative agreement between CABI, ICAR and DARE and of all survey visits by UK staff. The NBA is a statutory autonomous body under the Ministry of Environment, Forests and Climate Change, that the Government of India established in 2003 to implement the provisions under the Biological Diversity Act, 2002, after India signed CBD in 1992.

As well as working with ICAR institutes, the Hedychium project has been working in Sikkim, India with the Government of Sikkim and Sikkim University for collection of natural enemies. An MoU with the university, as well as collection permits issued by the Research, Evaluation and Monitoring Cell (REMC), Forest Secretariat, Gangtok, were obtained for every survey, with notifications sent to the Sikkim Biodiversity Board. Officially sanctioned collaborations with ICAR and Sikkim University and remuneration for support and facilitation have been ongoing since 2014.

Additionally, non-monetary benefits of all the biocontrol projects have included:

- sharing of R\&D results relevant to country needs, including scientific reports, identifications, and contribution of specimens to national collections, including many species new to science;

- collaboration in education, training, R\&D programmes. Training opportunities have been facilitated and mentoring of collaborators has been delivered by UK staff in the field through joint surveys as well as patronage of MSc and PhD students by the projects. CABI and collaborating project staff have been funded by the projects to attend national and international conferences to enable them to share results;

- joint authorship of publications and joint ownership of intellectual property rights;

- project partners also benefited from access to ex situ facilities and to databases through CABI membership and links with the Natural History Museum (NHM), London; and

- transfer of scientific information, knowledge and technology; and institutional capacity development to help build or maintain local collections as described above.

Controlling floating pennywort in a safe and sustainable way. CABI's project website states: 'Floating pennywort, Hydrocotyle ranunculoides, is a strong contender for the title of worst aquatic weed in the UK. Originating from Central and South America, the plant arrived in the UK in the late 1980s as an oxygenating ornamental plant for the aquatic trade'. It impacts slow-flowing river systems and water bodies, forming dense vegetative mats, reducing the availability of oxygen in the water, threatening fish and invertebrates, choking drainage systems, crowding our native water plants and posing a risk to livestock, dogs and human health. The project sought to identify the safest and most effective biocontrol agent for floating pennywort through comprehensive host range testing in CABI's UK quarantine facilities. 
Biocontrol of floating pennywort for the UK is using natural enemies from Argentina and Paraguay (Cabrera Walsh et al. 2013). CABI is working with Fundación para el Estudio de Especies Invasivas (FuEDEI) in Argentina under a mutually agreed MTA; collection permits (for FuEDEI only) are in place for the weevil Listronotus elongatus, specimens of which were hand carried to the UK in 2014 (from Argentina) and 2019 (from Paraguay). Vouchers are deposited at the NHM, London with the required negotiated access and use agreements. This work has resulted in the following benefits being shared:

- partnerships built in Brazil, Argentina and Paraguay sharing non-monetary benefits;

- collaborative sub-contractual agreements with FuEDEl;

- funding that supported a PhD student and visits to CABI UK; and

- non-monetary benefits including: publications, results shared and opportunities for further joint project development.

Assessing the potential of natural enemies for control of Japanese knotweed. Japanese knotweed (Fallopia japonica) is a highly invasive species in the UK, mainland Europe, North America and parts of Oceania (Shaw et al. 2009). Introduced from Japan in the mid-19th century as a prized ornamental plant, the species soon became problematic in its entire exotic range exerting detrimental impacts on both the biodiversity and the local infrastructure. Due to its ability to form dense monocultures and to regrow from tiny fragments of rhizome, Japanese knotweed is often governed by special legislation in individual countries, for example in the UK where it is illegal to cause it to grow in the wild (Wildlife and Countryside Act 1981 - UK 1981). Japanese knotweed is also a frequent invader of riparian forests; it is particularly suited to these habitats and is an aggressive invader along watercourses. Currently, $F$. japonica can be partially controlled using chemicals, however, this is costly and considered as unsustainable due to the ease of spread of the plant and the increasing restrictions in the use of herbicides in many countries.

Classical biological control programmes targeting Japanese knotweed were initiated in the UK and the USA in 2000, followed by Canada in 2007 and by the Netherlands in 2013. From the suite of natural enemies associated with Japanese knotweed in its centre of origin, the psyllid Aphalara itadori and the fungal leaf-spot pathogen Mycosphaerella polygoni-cuspidati were selected as having the highest potential as biocontrol agents (Djeddour et al. 2008). The psyllid has already been released in the UK and in Canada, while the leaf-spot pathogen, having been rejected as a classical agent, is currently undergoing evaluation as a potential mycoherbicide.

Benefits originating from this initiative include training of a Japanese counterpart who completed his $\mathrm{PhD}$ on the pathology components of the project, joint research papers and presentations given in Japan on the research. Expansion of the project to include Canada and the USA, as well as most recently the Netherlands, has allowed further collaborative research and joint publications.

Use of a rust fungus for control of Himalayan balsam in the UK. Himalayan balsam (Impatiens glandulifera) is one of Europe's most invasive riparian weeds, particularly in the UK where it was introduced in the 19th century as an ornamental plant. Each plant can produce hundreds of seeds which are forcibly ejected up to $7 \mathrm{~m}$ away from the parent plant, leading to the development of dense monospecific stands. These monocultures of Himalayan balsam can have negative impacts on native biodiversity, by altering the soil microbial, invertebrate and plant communities (Tanner et al. 2013, 2014; Gaggini et al. 2018; Kiełtyk and Delimat 2019). As an annual plant, Himalayan balsam stands die back in the autumn and this may have impacts on soil erosion and siltation (Greenwood et al. 2020). Management of this weed is largely limited to manual control which can be successful if sustained for 
several years. If management is not carried out on a catchment scale, however, reinvasion is likely. The classical biological control programme for Himalayan balsam was initiated in 2006 when extensive surveys took place in the foothills of the Indian and Pakistani Himalayas for host-specific natural enemies (Varia et al. 2016).

One natural enemy, a rust fungus, which was observed causing significant impacts on Himalayan balsam was exported from India to the UK in 2010 to undergo extensive safety testing. Export was facilitated by the National Bureau of Plant Genetic Resources (NBPGR) in India and approved by the DARE (see 'wild gingers' for more detail). The rust Puccinia komarovii var. glanduliferae is an autoecious (completing its entire life cycle on a single species), macrocyclic, five-spore-staged rust fungus which infects the stem and leaves of Himalayan balsam throughout the growing season. The Indian strain of the rust was approved for release in England and Wales in 2014 (Ellison et al. 2020). Subsequently, a second strain from Pakistan, which was found to infect a different cohort of Himalayan balsam populations, was released in 2017. The results of the field releases show that the rust is able to overwinter and establish populations in stands of Himalayan balsam in England, however, the presence of several weed genotypes in the British Isles not susceptible to either rust strain requires additional strains to be identified in the native Himalayan range (Kurose et al. 2020). As a result, further collaborative surveys with scientists from the ICAR, the University of Kashmir and the University of Punjab are now taking place. Benefits shared to date include joint papers and training activities with Indian and Pakistani collaborators, plus collaborative payments made. Training was also provided to support an MSc student from Kenya and a PhD student from Malaysia. The project has also been extended to include control of Himalayan balsam in Canada.

Managing invasive Madagascar rubbervine in Brazil. Invasion by the alien plant Madagascar rubbervine (Cryptostegia madagascariensis) is endangering native flora and fauna in north-eastern Brazil (CABI 2021a). In the Caatinga area, the endemic Carnaúba palm, with its highly valued wax, has come under threat. $\mathrm{CABI}$, in collaboration with Brazilian counterparts, is seeking to evaluate the damaging rust Maravalia cryptostegiae, known to infect the vine in Madagascar, as a potential biocontrol agent for Madagascar rubbervine. An isolate of the same rust fungus was used to successfully control another rubbervine species (Cryptostegia grandiflora) in Australia and evidence suggests that this one is equally effective as it is anticipated to be specific, damaging and highly likely to have a similar impact. The objectives of the project are to undertake ecological and socio-economic baseline studies of the Madagascar rubbervine invasion in the Cereá State of north-eastern Brazil, to match the plant biotype with a virulent rust biotype, to assess the host specificity of the selected pathogen isolate against an agreed test plant list and to evaluate its safety as a potential biocontrol agent for introduction into Brazil. A field survey for the rust in Madagascar was conducted in collaboration with the Entomology Department of the University of Antananarivo, Madagascar, in April 2018. A monetary payment was made to the department as well as all expenses of two students met which accompanied the survey. Training in field plant pathology was given to the students of the university. Rust material collected during the survey was exported under licence to the UK, where, together with rust material from Kenya collected in the late 1980s and stored in liquid nitrogen at $C A B I$, it underwent evaluation to select the best-matched strain for the invasive biotype of Madagascar rubbervine present in Brazil for host-specificity testing. Brazil will not only ultimately benefit from a strain of $M$. cryptostegiae introduced, if approved, as a biocontrol agent, but also during the research phase from the scientific knowledge gained during the previous biocontrol project conducted for Australia using the same pathogen. This provides further evidence demonstrating that benefits from biological control are reciprocal, in the long run all countries allowing such use of their genetic resources can benefit for example when an invasive species threatens their biodiversity. 


\section{Summary}

The report highlights the value of the research work $C A B I$ carries out for the public good. In developing and delivery of its projects, regulations are followed in gaining access to, collection, conservation and utilization of genetic resources. This working paper provides an overview of CABI UK Centre projects active from 2019 that involve access to genetic resources, with updates in 2021. CABI relies heavily on complementary input for the delivery of many of its projects. Of the 200 projects involving genetic resources, the majority are with partners in the provider countries, often with joint funding. Fewer than 20 of these projects were in countries with Nagoya legislation and required compliance with ABS law. Details of 27 projects are provided that include genetic resources from 22 countries: Argentina; Australia; Brazil; Canada; Chile; China; Colombia; Gabon; Germany; Ghana; India; Japan; Kenya; Madagascar; Nepal; New Zealand; Pakistan; Paraguay; the Netherlands; Trinidad and Tobago; UK; and Zambia. Of these countries 17 are party to the Nagoya Protocol but only nine have law implementing it, the remaining countries are not party, yet $C A B I$ shares benefits with all, complying with law but also with the spirit of the CBD.

Information is also provided on deposits made into CABI's living collection which holds 28,000 strains of fungi and 2000 strains of bacteria collected from over 140 countries, over $50 \%$ from CABI's member countries. Over 23,000 of these strains were collected pre-CBD with only 281 strains from 26 countries outside the UK being deposited in the collection since the Nagoya Protocol became effective on 12 October 2014. Any terms or conditions on use are recorded and these govern the future use of the genetic resource.

The output of all CABI's work is aimed at improving people's lives worldwide by providing information and applying scientific expertise to solve problems in agriculture and the environment. The approach involves putting information, skills and tools into people's hands. CABI's 50 member countries guide and influence our work which is delivered by scientific staff based in our global network of centres. A proportion of CABI's projects include the use of genetic resources which it acquires in compliance with the Nagoya Protocol adhering to CABI policy and best practice to meet country requirements and deliver its mission.

\section{Acknowledgements}

We gratefully acknowledge the funding provided for this research by the CABI Development Fund. $C A B I$ is an international intergovernmental organization, and we gratefully acknowledge the core financial support from our member countries (and lead agencies) including the United Kingdom (Foreign, Commonwealth and Development Office), China (Chinese Ministry of Agriculture and Rural Affairs), Australia (Australian Centre for International Agricultural Research), Canada (Agriculture and Agri-Food Canada), the Netherlands (Directorate-General for International Cooperation), and Switzerland (Swiss Agency for Development and Cooperation). Full details are available at: http://www.cabi.org/about-cabi/who-we-work-with/key-donors/. 


\section{References}

Bridge, P.D., Smith, D. and Stackebrandt, E. (eds) (2021) Trends in the Systematics of Bacteria and Fungi. CAB International, Wallingford, UK, xviii + $346 \mathrm{pp}$. https://doi.org/10.1079/9781789244984.0000

CABI (CAB International) (2018a) CABI ABS Policy. Available at: https://www.cabi.org/wpcontent/uploads/PDFs/AboutCABI/Cabi-Abs-Policy-Draft-For-Website-May2018.pdf (accessed 9 August 2020).

CABI (CAB International) (2018b) Controlling wild ginger. CABI, Projects. Available at: https://www.cabi.org/projects/controlling-wild-ginger/ (accessed 07/09/2021).

CABI (CAB International) (2021a) Managing invasive Madagascar rubbervine in Brazil. Available at: https://www.cabi.org/projects/managing-invasive-madagascar-rubbervine-in-brazil/ (accessed 23 August 2021).

CABI (CAB International) (2021b) Major oilseed rape pests targeted in CABI Biopesticide project. Available at: https://chap-solutions.co.uk/projects/major-oilseed-rape-pests-targeted-in-cabibiopesticide-project/ (accessed 18 August 2021).

CABI (CAB International) (2021c) CABI's Genetic Resource Catalogue. Available at: https://platform.cabi.org/services/microbial-services/culture-collection-microorganismsupply/grc/ (accessed 28 January 2021).

CABI (CAB International) (2021d) Who are our Member Countries? Available at: https://www.cabi.org/about-cabi/membership/member-countries/ (accessed 23 August 2021).

CABI (CAB International) (2021e) Where we work. Available at: https://www.cabi.org/what-wedo/where-we-work/ (accessed 23 August 2021).

Cabrera Walsh, G., Maestro, M., Dalto, Y.M., Shaw, R., Seier, M., Cortat, G. and Djeddour, D.H. (2013) Persistence of floating pennywort patches (Hydrocotyle ranunculoides, Araliaceae) in a canal in its native temperate range: effect of its natural enemies. Aquatic Botany 110, 78-83. https://doi.org/10.1016/j.aquabot.2013.05.011

CBD (Convention on Biological Diversity) (2020a) Notification. Preparations to mark the 10-year anniversary of the adoption of the Nagoya Protocol. Ref: SCBD/NPU/WY/MD/88952. Available at: https://www.cbd.int/doc/notifications/2020/ntf-2020-041-np-en.pdf (accessed 9 August 2020).

CBD (Convention on Biological Diversity) (2020b) Digital sequence information on genetic resources. Available at: https://www.cbd.int/dsi-gr/ (accessed 9 August 2020).

CHAP (Crop Health and Protection Limited) (2020) Innovations to feed the future. Available at: https://chap-solutions.co.uk/ (accessed 9 August 2020).

Djeddour, D.H., Shaw, R.H., Evans, H.C., Tanner, R.H. and Seier, M. (2008) Could Fallopia japonica be the first target for classical weed biocontrol in Europe? In: Julien, M.H., Sforza, R., Bon, M.C., Evans, H.C., Hatcher, P.E., Hinz, H.L. and Rector, B.G. (eds) Proceedings of the XII International Symposium on Biological Control of Weeds, La Grande Motte, France, 22-27 April 2007. CAB International, Wallingford, UK, pp.463-469. https://doi.org/10.1079/9781845935061.0463

EC (European Commission) (2015) Commission Implementing Regulation (EU) 2015/1866 of 13 October 2015 laying down detailed rules for the implementation of Regulation (EU) No 511/2014 of the European Parliament and of the Council as regards the register of collections, 
monitoring user compliance and best practices. Official Journal of the European Union C275, 4-19. http://data.europa.eu/eli/reg impl/2015/1866/oj

EC (European Commission) (2016) Guidance document on the scope of application and core obligations of Regulation (EU) No 511/2014 of the European Parliament and of the Council on the compliance measures for users from the Nagoya Protocol on Access to Genetic Resources and the Fair and Equitable Sharing of Benefits Arising from their Utilisation in the Union.

Official Journal of the European Union C313, 1-19. https://eur-lex.europa.eu/legalcontent/EN/TXT/?uri=CELEX\%3A52016XC0827\%2801\%29\&qid=1629729386007

EC (European Commission) (2019) General Guidance, Revision 7 November 2019 Information from European Union Institutions, Bodies, Offices and Agencies, European Commission; general information. Available at:

https://ec.europa.eu/environment/nature/biodiversity/international/abs/legislation en.htm (accessed 07/09/2021).

Ellison, C.A., Pollard, K.M. and Varia, S. (2020) Potential of a coevolved rust fungus for the management of Himalayan balsam in the British Isles: first field releases. Weed Research 60, 37-49. https://doi.org/10.1111/wre.12403

Gaggini, L., Rusterholz, H.P. and Bau, B. (2018) The invasive plant Impatiens glandulifera affects soil fungal diversity and the bacterial community in forests. Applied Soil Ecology 124, 335-343. https://doi.org/10.1016/i.apsoil.2017.11.021

Greenwood, P., Gange, A.C. and Kuhn, N.J. (2020) Evidence of sedimentation inequality along riparian areas colonised by Impatiens glandulifera (Himalayan balsam). Weed Research 60, 26-36. https://doi.org/10.1111/wre.12397

Hinz, H., Weyl, P., Smith, D. and Djeddour, D. (2019) The Nagoya Protocol: implications for classical biological control of invasive plant species. In: Hinz, H., Bon, M.C., Bourdôt, G., Cristofaro, M., Desurmont, G., et al. (eds) Proceedings of the XV International Symposium on Biological Control of Weeds, Engelberg, Switzerland, 26-31 August 2018. Organising Committee XV International Symposium on Biological Control of Weeds 2018, Engelberg, Switzerland, pp. 206-211. https://bugwoodcloud.org/resource/files/15115.pdf

Kiełtyk, P. and Delimat, A. (2019) Impact of the alien plant Impatiens glandulifera on species diversity of invaded vegetation in the northern foothills of the Tatra Mountains, Central Europe. Plant Ecology 220, 1-12. https://doi.org/10.1007/s11258-018-0898-z

Kirk, P., Cannon, P., Minter, D. and Stalpers, J. (eds) (2011) Ainsworth and Bisby's Dictionary of the Fungi, 10th edn. CAB International, Wallingford, UK, xii + 771 pp. https://doi.org/10.1079/9780851998268.0000

Kurose, D., Pollard, K.M. and Ellison, C.A. (2020) Chloroplast DNA analysis of the invasive weed, Himalayan balsam (Impatiens glandulifera), in the British Isles. Scientific Reports 10, 10966. https://doi.org/10.1038/s41598-020-67871-0

Lowe, S., Browne, M., Boudjelas, S. and De Poorter, M. (2000) 100 of the World's Worst Invasive Alien Species: a Selection from the Global Invasive Species Database. The Invasive Species Specialist Group (ISSG), a specialist group of the Species Survival Commission (SSC) of the World Conservation Union (IUCN), Auckland, New Zealand, 12 pp. http://www.issg.org/pdf/publications/worst 100/english 100 worst.pdf

Rentería, J.L., Gardener, M.R., Panetta, F.D., Atkinson, R. and Crawley, M.J. (2012) Possible impacts of the invasive plant Rubus niveus on the native vegetation of the Scalesia Forest in the Galapagos Islands. PLoS ONE 7(10): e48106. https://doi.org/10.1371/journal.pone.0048106 
Shaw, R.H., Bryner, S. and Tanner, R. (2009) The life history and host range of the Japanese knotweed psyllid, Aphalara itadori Shinji: potentially the first classical biological weed control agent for the European Union. Biological Control 49, 105-113.

https://doi.org/10.1016/i.biocontrol.2009.01.016

Smith, D., da Silva, M., Jackson, J. and Lyal, C. (2017) Explanation of the Nagoya Protocol on Access and Benefit Sharing and its implication for microbiology. Microbiology 163, 289-296. https://doi.org/10.1099/mic. 0.000425

Smith, D., Hinz, H., Mulema, J., Weyl, P. and Ryan, M.J. (2018) Biological control and the Nagoya Protocol on access and benefit sharing - a case of effective due diligence. Biocontrol Science and Technology 28, 914-926. https://doi.org/10.1080/09583157.2018.1460317

Smith, D., Kermode, A., Cafà, G., Buddie, A., Caine, T. and Ryan, M.J. (2020) Strengthening mycology research through coordinated access to microbial culture collection strains. CABI Agriculture and Bioscience 1, 1-17. https://doi.org/10.1186/s43170-020-00004-9

Tanner, R.A., Varia, S., Eschen, R., Wood, S., Murphy, S.T. and Gange, A.C. (2013) Impacts of an invasive non-native annual weed, Impatiens glandulifera, on above-and below-ground invertebrate communities in the United Kingdom. PLoS ONE 8(6): e67271. https://doi.org/10.1371/journal.pone.0067271

Tanner, R.A., Ellison, C.A., Seier, M.K., Kovács, G.M., Kassai-Jáger, et al. (2014) Puccinia komarovii var. glanduliferae var. nov.: a fungal agent for the biological control of Himalayan balsam (Impatiens glandulifera). European Journal of Plant Pathology 141, 247-266. https://doi.org/10.1007/s10658-014-0539-x

UK (Government of United Kingdom) (1981) Wildlife and Countryside Act. Available at: https://www.rspb.org.uk/birds-and-wildlife/advice/wildlife-and-the-law/wildlife-andcountryside-act/

UK (Government of United Kingdom) (2015) The Nagoya Protocol (Compliance) Regulations 2015. Available at: https://www.legislation.gov.uk/uksi/2015/821/contents/made (accessed 9 August 2020).

UK (Government of United Kingdom) (2021) Regulations: The Nagoya Protocol on access and benefit sharing (ABS). Available at: https://www.gov.uk/guidance/abs (accessed 9 August 2020).

Varia, S., Pollard, K. and Ellison, C. (2016) Implementing a novel weed management approach for Himalayan balsam: progress on biological control in the UK. Outlooks on Pest Management 27, 198-203. https://doi.org/10.1564/v27 oct 02

Verkley, G., Martin, D. and Smith, D. (2016) Microbial Resource Research Infrastructure [MIRRI] Best Practice Manual on Access and Benefit Sharing. Published online by Zenodo. Available at: https://doi.org/10.5281/zenodo.284881 (accessed 25 August 2021).

Wagner, W.L., Herbst, D.R. and Sohmer, S.H. (1999) Manual of the Flowering Plants of Hawaii, revised edn. University of Hawaii Press/Bishop Museum Press, Honolulu, Hawaii, 1919 pp. https://uhpress.hawaii.edu/title/manual-of-the-flowering-plants-of-hawaii-revised-edition/ 


\section{contact CABI}

\section{Africa}

Kenya

CABI, Canary Bird

673 Limuru Road, Muthaiga

PO Box 633-00621

Nairobi, Kenya

T: +254 (0)20 2271000/ 20

E: africa@cabi.org

\section{Ghana}

CABI, CSIR Campus

No. 6 Agostino Neto Road

Airport Residential Area

P. O. Box CT 8630, Cantonments

Accra, Ghana

T: +233 (0)302 797202

E: westafrica@cabi.org

Zambia

CABI, Southern Africa Centre

5834 Mwange Close

Kalundu

P.O. Box 37589

Lusaka, Zambia

T: +260967619665

E: westafrica@cabi.org

\section{Americas}

Brazil

CABI, UNESP-Fazenda Experimental Lageado, FEPAF (Escritorio da CABI)

Rua Dr. Jose Barbosa de Barros 1780

Fazenda Experimental Lageado

CEP:18.610-307

Botucatu, São Paulo, Brazil

T: +5514-38826300

E: y.colmenarez@cabi.org

Trinidad \& Tobago

CABI, Gordon Street, Curepe

Trinidad and Tobago

T: +18686457628

E: caribbeanLA@cabi.org

USA

CABI, 745 Atlantic Avenue

8th Floor, Boston,

MA 02111, USA

T: +1 (617) 682-9015

E: cabi-nao@cabi.org

\section{Asia}

China

CABI, Beijing Representative Office

Internal Post Box 85

Chinese Academy of Agricultural Sciences

12 Zhongguancun Nandajie

Beijing 100081, China

T: +86 (0)10 82105692

E: china@cabi.org

\section{India}

CABI, 2nd Floor, CG Block,

NASC Complex, DP Shastri Marg

Opp. Todapur Village, PUSA

New Delhi - 110012, India

T: +91 (0)1125841906

E: cabi-india@cabi.org

Malaysia

CABI, PO Box 210,

43400 UPM Serdang

Selangor, Malaysia

T: +60 (0)3 89432921

E: cabisea@cabi.org

Pakistan

CABI, Opposite 1-A,

Data Gunj Baksh Road

Satellite Town, PO Box 8

Rawalpindi, Pakistan

T: +92 (0)519290132

E: sasia@cabi.org

\section{Europe}

Switzerland

CABI, Rue des Grillons 1

$\mathrm{CH}-2800$ Delémont, Switzerland

T: + 41 (0)32 4214870

E: europe-CH@cabi.org

UK

CABI, Nosworthy Way

Wallingford, Oxfordshire, OX10 8DE, UK T: +44 (0)1491832111

E: corporate@cabi.org

CABI, Bakeham Lane

Egham, Surrey, TW20 9TY, UK

T: + 44 (0)1491 829080

E: cabieurope-uk@cabi.org

E:microbialservices@cabi.org 